\title{
Formación e internacionalización de la gran empresa cárnica española, 1944-2008: Campofrío
}

\section{Formation and internationalization of the large Spanish meat processing companies, 1944-2008: Campofrío}

\author{
JAVIER MORENO LÁZARO \\ Universidad de Valladolid
}

\begin{abstract}
RESUMEN
Campofrío era en 2000 la mayor empresa cárnica de la Unión Europea y figuraba entre las más importantes del mundo. Muy pocas

empresas manufactureras o alimenticias españolas tenían una posición similar en el

mercado europeo. Este trabajo pretende esclarecer las claves de una historia tan corta como exitosa. Mi propósito es probar que tal fue el resultado de sus virtudes gerenciales y

productivas y, muy especialmente, de su

política de colaboración con las empresas competidoras. No obstante, Campofrío fracasó en su conquista de Latino América. Su estudio puede ofrecer una visión menos épica de la extensión de las empresas españolas en ese Continente en las últimas décadas del siglo $\mathrm{XX}$, al tiempo que proporciona nuevas noticias sobre su crecimiento en la Europa del Este.
\end{abstract}

PALABRAS CLAVE: Historia de la Empresa, Industria Cárnica, Gerencia, Estructura de Mercado, España Códigos JEL: L3, L22, N64, N84

\section{ABSTRACT}

Campofrío was at 2000 the biggest UE meat processing company and were included between the most important in the world. Just a few manufacturing or food Spanish companies had a similar presence in the European market. This paper wants to looks into the reasons of a short and successfully history. I try to proof that that was the consequence of its managerial and productive virtues and, most of all, its collaboration policy with other Spanish firms which belonged to the same sector. Nevertheless, Campofrio failed in its conquest of Latin America market. Its study could offer a less epic perspective of Spanish companies' extension in this Continent during the last decades of the $20^{\text {th }}$ century as well as give news references on their growth in West European countries.

KEY WORDS: Business History, Meat Processing Industry, Management, Market Structure, Spain

JEL Codes: L3, L22, N64, N84 


\section{Introducción ${ }^{1}$}

$\mathrm{E}$ s conocida la contribución de la industria cárnica a la modernización de la empresa occidental, particularmente desde 1880 en adelante ${ }^{2}$. Este sector alumbró en Chicago los cambios organizativos y tecnológicos inherentes a la producción en serie. Las grandes empresas transformadoras integraron verticalmente la crianza de ganado. Los controles de calidad y salubridad dictados por la Administración y la amenaza de epidemias obligaron a estas firmas a investigar en biotecnología y sanidad animal, por lo que estuvieron entre las pioneras en la creación de departamentos de I+D.

La mayor (si no la única) aportación de nuestro país a la modernización institucional del negocio cárnico se originó justamente en el sector porcino. No en balde las empresas españolas dedicadas a este giro gozaban a la altura de 2000 de un nivel de implantación en el mercado europeo muy superior al del resto de las empresas agroalimentarias de escasa elaboración ${ }^{3}$. Sin embargo, poco sabemos de su trayectoria.

En este trabajo refiero la historia de la mayor de ellas: Campofrío. En el transcurso de seis décadas, las que mediaron de su nacimiento en 1944 a los comienzos del siglo XXI, Campofrío pasó de ser la modesta titular de un matadero local a la primera de las cárnicas europeas, tanto en volumen de facturación como en extensión territorial.

En este texto pretendo identificar las claves de tal éxito en una actividad hostil (al menos en España) a la formación de la gran empresa. Sostengo la tesis de que la capacidad con la que Campofrío supo adaptarse a las mutaciones de la demanda, explorar mercados emergentes e incorporar los cambios gerenciales y organizativos ensayados en Estados Unidos, así como su política de colaboración con firmas competidoras y proveedoras, le izaron a la cabeza de las firmas del sector.

El estudio de Campofrío presenta un interés añadido, en tanto que ejemplifica el proceso de internacionalización de la empresa alimentaria española, oscurecido por el de las corporaciones financieras, constructoras o energéticas. Aspiro a demostrar que su integración en el mercado mundial fue mucho más tortuosa y no siempre se vio convenientemente recompensada.

Al tiempo, su consideración desvela los límites al crecimiento endémicos a la empresa familiar y los instrumentos empleados para su financiación, acceso a la tec-

[Fecha de recepción del original, mayo de 2008. Versión definitiva, enero de 2008].

1 He podido realizar este trabajo gracias la ayuda prestada por el proyecto de investigación Empresas y empresarios de Castilla y León, siglos XVI-XX (Junta de Castilla y León, VA-050-A06), dirigido por Ángel García Sanz. Debo asimismo reconocer la contribución de los evaluadores de la revista a la mejora de este texto.

2 Rixson (2000), pp. 235-242, Parren (2006), pp. 30-57, Skaggs (1988), pp. 90-129, Yeager (1981), Walsh (1982) y Azzam y Anderson (1996).

3 Ministerio de Agricultura, Pesca y Alimentación (2006). 
nología y penetración exterior. Mi texto se detiene en analizar cómo solventó esta firma el reto de la sucesión y cómo compatibilizó (cuando lo hizo) la integración horizontal con el mantenimiento del orden inherente al parentesco.

Así pues, en este trabajo pondré el acento en el análisis de los aspectos institucionales. Sólo colateralmente ilustra los vertiginosos cambios en la alimentación que ha experimentado la sociedad española desde la eliminación en 1952 del racionamiento hasta finales del siglo $\mathrm{XX}$, en lo que a los embutidos se refiere, en tanto que ya han sido descritos cabalmente por la historiografía ${ }^{4}$. Por la misma razón, tampoco me detengo en la evolución de la cabaña ganadera más que de soslayo.

En el texto expongo y defiendo mis tesis atendiendo a un criterio cronológico. En los tres primeros capítulos refiero la historia de la empresa en los años del franquismo en los que se fraguó su hegemonía. A las transformaciones incitadas por las respuestas a las crisis energéticas, el cambio generacional y la incorporación de España a la CEE dedico los tres siguientes. Por último, me ocupo de narrar el proceso de internacionalización e integración horizontal en la era de la globalización.

\section{Los orígenes, 1944-1951}

El nacimiento de Campofrío fue el fruto de uno de esos atrabiliarios y megalómanos proyectos empresariales que menudearon en la España de la postguerra, al calor de la política industrial autárquica y del propio apoyo del Estado, tan entusiastas como carentes del menor fundamento económico.

$\mathrm{Su}$ relato requiere, si quiera, una somera síntesis de los primeros pasos de la industria cárnica española. Mientras que los mataderos públicos levantados desde 1905 en adelante incorporaron las nuevas técnicas estadounidenses en el sacrificio, la elaboración de embutidos y conservas cárnicas permanecía a comienzos de siglo XX ajena al cambio técnico ${ }^{5}$. La demanda de estos productos, un lujo muy exclusivo que solo podían permitirse las familias de mayor caudal, era satisfecha por carniceros y chacineros a escala local. Las restricciones al tráfico de carnes, impuestas por las corporaciones municipales, jueces y partes en el negocio, entorpecieron la implantación de la economía de fábrica6 ${ }^{6}$.

4 Véase el compendio bibliográfico de Varela (2000), así como Gómez Mendoza y Simpson (1988) y Nicolau y Pujol (2004) para los años previos a la Guerra Civil.

5 Sanz Egaña (1940), pp. 13-14 y Gómez Mendoza (1994), pp. 269-272.

6 Gómez Mendoza (1994), p. 274. 
Sólo en la década de 1920, y al abrigo de la diversificación de la dieta que provocó el aumento de la renta disponible, algunas firmas chacineras rebasaron los fronteras provinciales e, incluso, nacionales. Tal fue el caso de las navarras Mina (1934) y Pamplonica (1928), la murciana Bernal, Postigo de Cantimpalos (Segovia) y de los acreditados propietarios de secadores de jamón de Guijuelo (Salamanca), Teruel, Jabugo (Huelva) y Trévelez (Granada) 7 . Pero estos productores empleaban procedimientos artesanales, por más que generasen un elevado valor añadido.

Cataluña, una vez más, fue la cuna de la empresa cárnica en cuanto tal, gracias a la feliz conjunción de un elevado grado de urbanización, la especialización porcina, así como a las economías externas que irradiaba su industria alimentaria ${ }^{8}$. La disponibilidad de energía eléctrica también fue determinante. En 1931 Productos Selectos del Cerdo S.A., fundada en Manlleu 1924 por las familias Roqué y Colomer, comenzó la distribución de embutidos y fiambres en envases de lata y cristal, bajo la denominación de La Piara ${ }^{9}$. Poco después, Alberto Kopke elaboró por primera vez en España jamón cocido en su planta de Figueras (Gerona) ${ }^{10}$.

El inicio de la Guerra Civil abortó tales cambios empresariales y tecnológicos. A los fatales efectos de la contienda en la cabaña, se unieron los de una torpe ordenación estatal del mercado, aún más aciagos. En 1939 el Ejecutivo prohibió, en la práctica, la producción de embutidos, en el convencimiento de que su continuidad podría "restar existencias al consumo en fresco y elevar considerablemente su precio"11. Las empresas más veteranas tuvieron que clausurar sus instalaciones, operar en la clandestinidad o cambiar de actividad, como la murciana Embutidos Bernal, dedicada desde 1941 a la elaboración de jabón ${ }^{12}$.

Por el contrario, el Gobierno fomentó la producción de conservas y jugos cárnicos, hasta entonces importados de Uruguay, por razones estratégicas ${ }^{13}$. Durante la Guerra Civil se habían detectado problemas en el abastecimiento de estos alimentos en el "bando nacional", solventados por algunos gobernadores civiles con la formación bajo su tutela de empresas transformadoras ${ }^{14}$. Resultaba, pues, preciso incentivar el desarrollo de una industria de compuestos cárnicos en manos españolas,

7 Oficina Española de Patentes y Marcas (OEPM en adelante), marcas 1.953 y 74.720, Hernández y Crespo (1991), p. 109, Bello (1997), Vega (2003), Eurocarne (2003) y Heraldo Segoviano, 1-1-1928 (suplemento). Pujol (2002) y (2003), pp. 265-266, Izquierdo (1972), Torrado (1985), y Castell (2001).

OEPM, Patentes, expediente 117.491 y marca 68.530 y RMB, hoja 15.491.

Archivo General de la Administración (AGA en adelante), Industria, legajo 71/5.522, expediente 9.684.

AGA, Industria, legajo 71/5.406, expediente 5.156.

AGA, Industria, legajo 71/5.369, expediente 3.500 .

Eran obtenidos en la planta de la firma británica Liebniz en Fray Bentos. Sobre el suministro de compuestos cárnicos a los Ejércitos europeos en el primer tercio del siglo XX véase Parren (1978), pp. 206-212, (2006), pp. 59-67 y Sanz Eguña (1940), pp. 294-309.

14 Tal fue el caso de Tocinera Andaluza, creada en Camas (Sevilla) en 1937. 
siguiendo expresamente el ejemplo y los consejos del Gobierno alemán ${ }^{15}$. El suministro a cuarteles, hospitales y colegios militares, así como a los comedores del Auxilio Social, a juicio de las autoridades, habría de efectuarse con productos del país.

El problema estribaba en que las fábricas catalanas no podían hacerlo, debido a la carencia de materias primas. Es más, su ubicación, con arreglo a las exigencias de la defensa nacional que esgrimía el Ejecutivo, resultaba inconveniente ${ }^{16}$. Tanto fue así que la familia Kopke tuvo que cerrar en 1942 su planta de Figueras y reabrirla en Cótana (Málaga) ${ }^{17}$. Los mismos obstáculos sufrieron los productores valencianos. El mayor de ellos, José Marqués Cuñat, trasladó en 1945 de Tabernes Blanques a Ginzo de Limia (Orense) su factoría, si bien la devolvió a su emplazamiento primitivo transcurridos dos años ${ }^{18}$.

El Gobierno tuvo, pues, que improvisar. En 1941 autorizó al calabrés Bruno Botello Pellicano a instalar una fábrica de compuestos cárnicos en Madrid y tramitó la apertura de una segunda en Tafalla (Navarra) dos años más tarde ${ }^{19}$. Como quiera que su producción resultara insuficiente, el Ministerio de Industria confió a Gegrorio Loste Isern la tarea de crear una gran empresa con esta misión en Burgos.

Loste se había visto obligado a trasladar, debido a las mismas imposiciones de la Intendencia, en 1941 su fábrica de galletas de Sant Martí de Provençals (Barcelona) a Burgos, so pena de subrogarse forzosamente a las obligaciones financieras contraídas por la UGT durante la Guerra Civil, en que fue colectivizada ${ }^{20}$. En compensación, el Ministerio de Industria le permitió en 1944 la construcción en Burgos de un matadero y una planta de elaboración de conservas cárnicas.

Loste formó, a tal fin y junto con varios inversores burgaleses, catalanes y madrileños, en ese año Conservera Campofrío, con un capital de un millón de pese$\operatorname{tas}^{21}$. Parecía un negocio seguro. La nueva empresa aprovecharía las redes de comercialización de Loste (tal y como figuró expresamente en los estatutos) y su propio prestigio para distribuir la carne $\mathrm{e}^{22}$. Y las ventas a la Administración estaban apalabradas de antemano.

Al cabo, el intento de Loste resultó un fiasco. El catalán carecía de la maquinaria precisa para la obtención de estas mercancías. Es más, La Piara consiguió sortear el ninguneo de la Administración, gracias a la pericia técnica de Ramón Dordal,

\footnotetext{
15 AGA, Industria, legajo 71/5399, expediente 3.698.

Véase San Román (1999).

AGA, Industria, legajo 71/5.522, expediente 9.684 .

AGA, Industria, legajos 5486, expediente 8413 y 5.609, expediente 13.131.

AGA, Industria, legajos 71/5.222, expediente 9.684 y legajo 5.379.

Registro Mercantil de Burgos (RMBU en adelante), hoja 385.

RMBU, hoja 462.

Ibídem.
} 
cerrándole el paso por completo ${ }^{23}$. Así las cosas, la producción anual de Campofrío no llegó nunca a los 100 quintales métricos de unos compuestos cárnicos de baja calidad, lo que representó poco más de un $1 \%$ de la capacidad de sus instalaciones ${ }^{24}$.

\section{El cambio de manos y de negocio, 1952-1960}

Las trabas a la producción de embutidos no pudieron tener consecuencias más funestas: el número de cerdos sacrificados cayó en un 36,8\% entre 1939 y $1946^{25}$. El Gobierno hubo de rectificar. Gracias a ello, a finales de la década de 1940, las empresas chacineras salieron de su letargo, particularmente en la sierra soriana (caso de Industrias Revilla y Moncayo, de Ólvega) y en el pre-Pirineo catalán (Espuña y Noel, en Olot), comarcas ambas favorecidas por su singular climatología, muy adecuada para el curado del jamón ${ }^{26}$.

Sin embargo, no pudieron reanudar la producción a cierta escala debido a las dificultades en el aprovisionamiento de canales. El Gobierno tan sólo alcanzó a autorizar la matanza de cerdos en los meses de invierno. Por su parte, la Comisaría de Abastecimientos y Transporte (CAT) dictó todo un arsenal de medidas para alentar la industria de transformados cárnicos bovinos y ovinos, pero se olvidó por completo del sector porcino ${ }^{27}$. El mismo desdén y ceguera inspiraron la redacción en 1951 por el INI del Plan de Red Frigorífica Nacional ${ }^{28}$.

El empresario abulense originario de Bilbao, José Luis Ballvé Goseascoechea (1919), percatado de las enormes posibilidades de lucro en la venta de carnes de cerdo en canal, decidió dedicarse a este negocio, renunciando a una prometedora carrera como editor en América, bajo la disciplina de Afrodisio Aguado, que estaba a punto de emprender.

Ballvé necesitaba exclusivamente un matadero. El de Campofrío, por sus dimensiones y ubicación, resultaba óptimo para la ejecución de su proyecto empresarial. En Burgos encontró también el caudal que precisaba: el aportado por Clemente Garay Eguía. En 1952 ambos compraron la empresa y sus instalaciones, tras abonar un millón de pesetas, un 58\% menos de lo que invirtió en su momento Loste.

OEPM, patentes 169.879 y 171.416.

Archivo Histórico Provincial de Burgos (AHPB en adelante), Abastos, Mapa Nacional de Abastos de 1945.

Ministerio de Agricultura (1953), p. 29.

OEPM, marcas 219.216 y 299.912.

AGA, Industria, legajo 71/5.406, expediente 5.156.

Gómez Mendoza (1995a), (1995b) y (2000); Comín y Martín Aceña (1991); Barciela, López y Melgarejo (2002), p. 92. 
Ballvé y su socio ofrecieron, por primera vez en España, el abasto diario de canales de carne fresca de cerdo a productores del norte del país, manteniendo la cadena de frío hasta el punto de entrega. Ello exigió la realización de cuantiosas inversiones en la adquisición de túneles de congelación y de camiones frigoríficos, dos amasadoras, una picadora y una sierra, así como en la edificación de dos grandes almacenes en Madrid y en Barcelona ${ }^{29}$. En pocos meses, Conservera Campofrío se ganó como clientes a los mayores chacineros castellanos, navarros, riojanos y gerundenses $^{30}$. Después de años de pérdidas continuas, en 1957 contabilizó, por primera vez, unos beneficios de 371.000 pesetas $^{31}$.

Esta anómala y excepcional posición de Campofrío en el mercado se prolongó tanto como tardó la Administración en corregir la rigidez de la oferta de canales de carne que ella misma había ocasionado.

A lo largo de la segunda mitad de la década de 1950, y al amparo de la recuperación de los ingresos familiares, surgieron nuevas empresas transformadoras del cerdo en Gerona (Casademont, 1955), Madrid (Cabo, 1959), Toledo (Tello, en 1955), Segovia (Acueducto, 1958), Navarra (Argal, 1960) y Murcia (El Pozo, de Tomás Fuertes, en Alhama, 1955) ${ }^{32}$. Otras, como La Piara en 1957, ampliaron considerablemente sus instalaciones ${ }^{33}$. Sin embargo, su producción no podía crecer al ritmo que lo hacía la demanda, debido a los problemas en la adquisición de insumos.

Apremiado por las tensiones en el mercado cárnico, el Gobierno toleró en la Orden Ministerial de 31 de enero de 1955 la apertura de mataderos frigoríficos privados y aprobó por fin el 22 de febrero de 1957 el Plan de Red Frigorífica Nacional, que dormía, en la práctica, el sueño de los justos en los cajones de los despachos ministeriales desde hacía más de un lustro ${ }^{34}$.

En 1956 el INI reformó un matadero municipal en Mérida, mientras que el ya mencionado José Marqués Cuñat promovió un año más tarde la constitución de Frigorífico Marqués, S.A..$^{35}$. Los chacineros gerundenses, con el consentimiento de los Sindicatos Verticales, pretendían también organizar un matadero frigorífico cooperativo. La iniciativa no fraguó, pero sí la de montar uno de dimensiones aún mayores en Seo de Urgel ${ }^{36}$. Y ello por detallar únicamente las inversiones potencialmente más dañinas para Campofrío.

AHPB, Hacienda, Memoria de Conservas Campofrío, 1957. Los legajos donde se encuentran estos documentos se detallan en la fuente del Gráfico 1. En lo sucesivo, indicaré sólo el año de la memoria.

AGA, Industria, Nuevas Industrias, legajo 71/6899.

Ibídem.

OEPM, marcas 273.639, 299.912, 364.822, 330.339 y 347.709, Registro Mercantil de Girona (RMGI en adelante), libro 34, folio 62, hoja 643, Martínez Carrión (1991) y Zapata (1986).

AGA, Industria, legajo 71/6.497, expediente 52.343.

Comín (2000), pp. 237-240; Barciela, López y Melgarejo (2004), p. 132 ; Alemany (1964), p. 65.

Registro Mercantil de Valencia (RMV en adelante), hoja 451 y Barciela, López y Melgarejo (2004), p. 145.

AGA, Industria, legajo 71/6.912, expediente 68.216. 


\section{GRÁFICO 1}

RENTABILIDAD ECONÓMICA Y DIVIDENDOS REPARTIDOS DE CAMPOFRÍO, 1957-1972

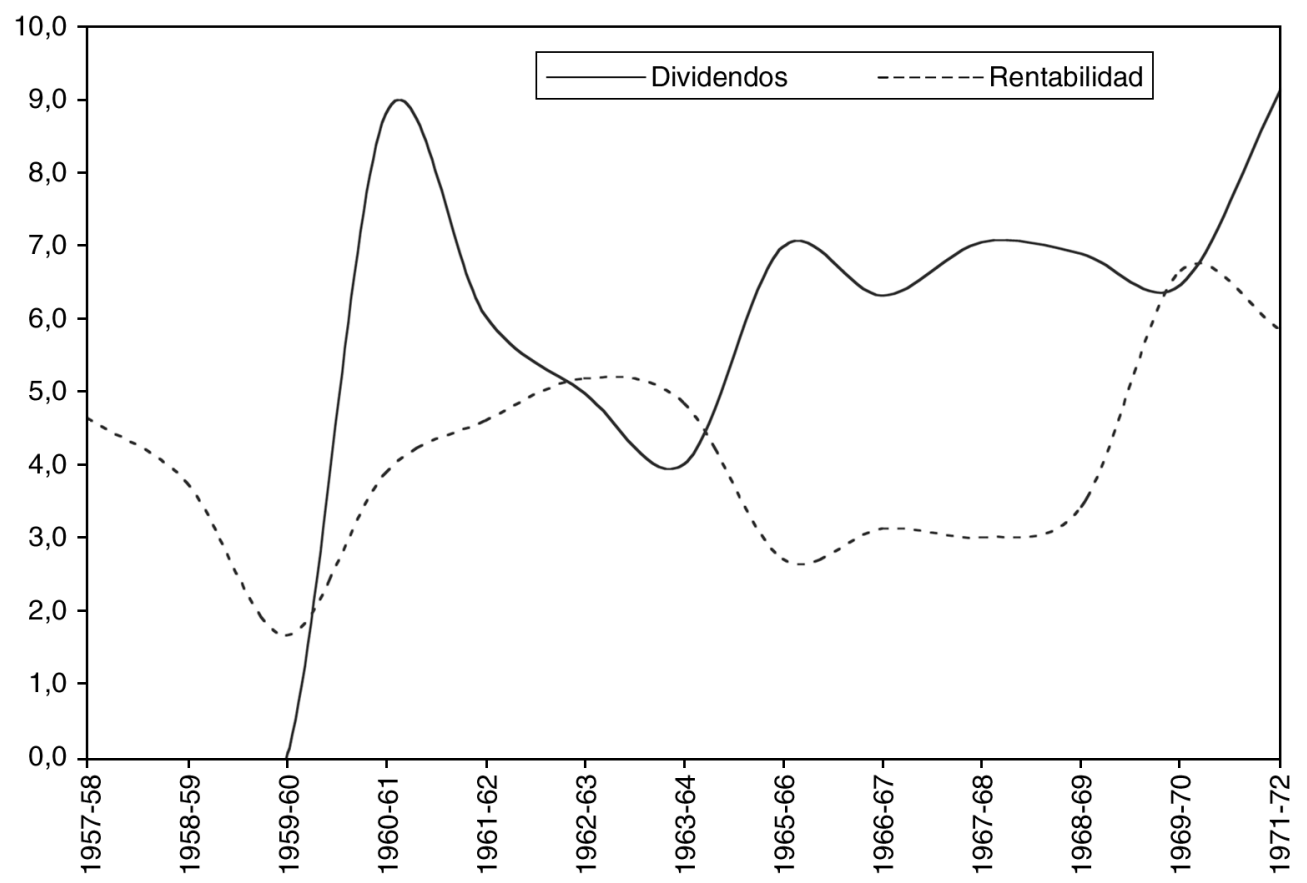

Fuente: AHPB, Hacienda, legajos 6486, 7191, 6557, 6211, 2290 y 1816, memorias de Conservas Campofrío y elaboración propia.

La burgalesa corría el riesgo de perder buena parte de sus mercados (sobre todo en Cataluña), justamente cuando afrontaba el encarecimiento de los costes y la caída de las ventas que comportó en el corto plazo la aplicación del Plan de Estabilización de 1959 (Gráfico 1). La empresa arrastraba serios problemas de competitividad. El precio medio de sus canales porcinas en 1960 (38,16 pesetas el kilogramo), superaba hasta en un $18 \%$ al percibido por sus competidoras murcianas, catalanas y valencianas $^{37}$. Tan delicada era la situación que Ballvé perdió varias fincas hipotecadas, debido al deterioro de su solvencia ${ }^{38}$.

37 Ministerio de Agricultura (1960), p. 31.
38 Memoria de 1960-61. 
Forzosamente Campofrío debía reducir esta brecha tecnológica. En 1960 Ballvé y Garay solicitaron permiso para convertir su matadero industrial en frigorífico y sacrificar en él también reses vacunas y ovinas. El INI se opuso firmemente a ello, con el argumento de que comprometería la actividad del recién inaugurado en León. Sin embargo, el Ministerio de Industria autorizó la edificación de la nueva planta ${ }^{39}$. Ballvé y Eguía desembolsaron 1,627.020 pesetas en la construcción de naves para la cría y engorde de 2.000 cerdos, chiqueros, tres cámaras refrigeradoras y dos grupos frigoríficos. El nuevo matadero, capaz de sacrificar al día 6.000 cerdos, era, de largo, el mayor de España.

\section{La americanización incompleta, 1961-1970}

A pesar de tamaña inversión, las dificultades para Campofrío persistieron en los primeros años de la década de 1960. La extensión de la peste porcina obligó en 1961 al Gobierno a importar canales y tocinos franceses y polacos ${ }^{40}$. Las subidas salariales aprobadas desde 1962, la escasez de mano obra femenina, la errática política de precios de la CAT y el resurgimiento del mercado negro contribuyeron también al empeoramiento de sus resultados (Gráfico 1) ${ }^{41}$. Tanto fue así, que en abril de 1962 parecía inevitable la liquidación de la empresa ${ }^{42}$.

La publicación en enero de 1963 del nuevo Plan de Red Ganadera de Frío Industrial mejoró las expectativas empresariales ${ }^{43}$. Ballvé estaba persuadido de que esta norma, que enterraba el Plan Frigorífico Nacional, no sólo liberalizaba el montaje de mataderos, sino que preludiaba una inminente relajación de la intervención, "desmesurada y arbitraria", de la CAT. Si tal cosa sucedía, la elaboración de productos cárnicos, muy competitivos, estaba llamada a ser un "gran negocio" 44 . Y ello debido al moderado precio de los productos porcinos y a la elevada relación marginal de sustitución entre la carne de cerdo y de vaca.

En tal convicción Ballvé, presidente del Consejo de Administración desde 1964, dispuso, con el auxilio del burgalés José Yartú González, un cambio en la estrategia que, en el corto plazo, disipó la amenaza de cierre. Básicamente, Ballvé americanizó su empresa, transplantando a Burgos los principios organizativos y productivos de las cárnicas de Chicago.

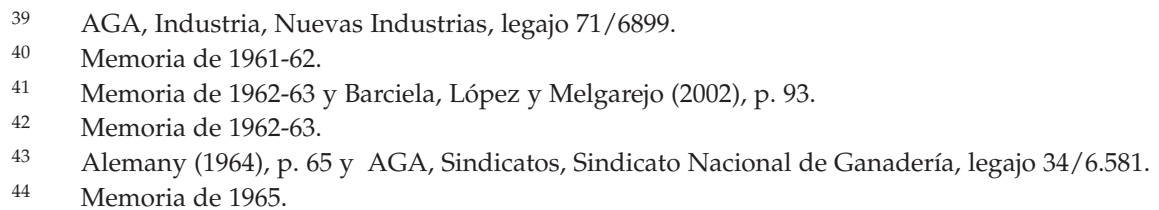


En 1965 amplió la fábrica, ya plenamente automatizada y con una plantilla que superaba el millar de personas, cinco veces más que en $1952^{45}$. Campofrío financió las obras con sucesivas ampliaciones de capital (en 1968 ascendía ya a 91 millones de pesetas), las ayudas públicas recibidas a través del Polo de Burgos y un préstamo del Banco de Crédito Industrial ${ }^{46}$. Ballvé estableció un nuevo patrón de relaciones laborales que concilió la ordenación en esta materia del Sindicato Nacional de Ganadería y el fordisimo ${ }^{47}$. En 1964 subsanó por completo los problemas en la captación de trabajadores cualificados con la apertura de su propia escuela de formación profesional ${ }^{48}$.

Ballvé relanzó la fabricación de embutidos, descuidada hasta entonces, a causa de la "aterradora" política de precios de la CAT. Eso sí, Campofrío evitó cocurrir con las firmas castellanas a las que surtía de canales. Desechado el chorizo, para no competir con Revilla, uno de sus mejores clientes de carne, y el jamón ibérico, Ballvé se especializó en la elaboración de jamón cocido, un producto muy asequible cuyo consumo procuraba la Administración y que únicamente La Piara elaboraba a muy pequeña escala ${ }^{49}$.

Por otra parte, Ballvé, en lugar de ofrecer el jamón cocido en piezas únicas, prohibitivas para gran parte las familias españolas, lo hizo en envases de lata más pequeños y permitió a los carniceros que lo vendiesen en lonchas. Para garantizar la frescura del jamón, empleó la misma cadena de conservación del frío de las canales de carne.

Ballvé impuso la política de "existencias cero"50. El producto debía salir de la planta con destino a las 15 delegaciones repartidas por toda la Península inmediatamente después del sacrificio o elaboración, con independencia del precio corriente. Con ello ambicionaba garantizar el suministro regular al cliente, ganar su fidelidad y reducir los gastos de almacenamiento ${ }^{51}$.

Los resultados de esta estrategia, basada en la innovación y en la no colusión, fueron excepcionales. Sus beneficios, en términos nominales, se multiplicaron entre 1958 y 1968 por 50. Y ello a pesar de que no hubo tal cambio en la política de la CAT, obsesionada por contener las tensiones inflacionarias y mantener los ingresos de explotación de las empresas ganaderas. Campofrío sacó provecho del aumento del

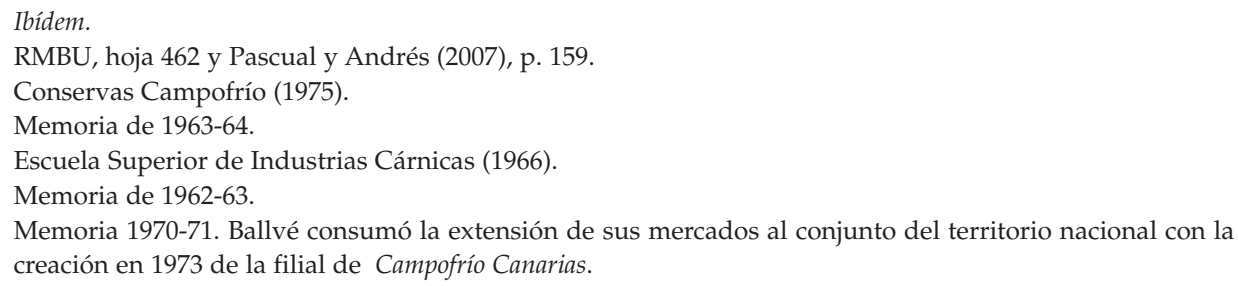
creación en 1973 de la filial de Campofrío Canarias. 
consumo de carne de cerdo (pasó de 12,3 kilogramos por persona y año en 1960 y año a 50,9 en 1973) por partida doble: a través del aumento de las ventas de jamón de York y las de canales. En 1970 Campofrío era ya, de largo, la mayor cárnica de España.

Ballvé supo beneficiarse de la posición privilegiada en el mercado que le otorgaba su condición de mayorista de canales, sancionada por el ejercicio de cargos de responsabilidad en el Sindicato Nacional de Ganadería. Las empresas chacineras se acomodaron con facilidad a una situación en virtud de la cual Campofrío asumía en exclusiva los costes de unas innovaciones de las que se beneficiaban ellas.

Sin embargo, Ballvé dejó una asignatura pendiente: el aprovisionamiento de ganado. Había conseguido el permiso para construir su macro matadero, pero a costa de consentir severas limitaciones en su trabajo. El Gobierno adjudicó el sacrificio de los excedentes porcinos de Galicia y Extremadura a los mataderos de León (para acallar las protestas del INI) y Cataluña, respectivamente ${ }^{52}$. Entre tanto, él tenía que adquirir "ganado de pesebre" en las pequeñas explotaciones de Burgos y Palencia, cada vez más escaso en pleno éxodo rural, incurriendo, no sólo en unos mayores costes de transacción, sino en el riesgo de verse afectado por la peste porcina.

Mientras Ballvé se inclinó por la contratación con pequeños criadores, el murciano Fuertes, ante las mismas contingencias, prefirió la integración vertical. En 1968 formó su propia granja porcina, adscrita a Cefusa, donde aplicó el denominado "sistema CIP" (Control Integral del Proceso), tomado de las cárnicas de Estados Unidos. Los cerdos eran cebados con piensos obtenidos en una planta de la empresa, sometidos a un permanente control sanitario por personal de la misma y sacrificados en su matadero ${ }^{53}$.

\section{La esclerosis, $1970-1982$}

Las empresas dedicadas a la elaboración de derivados del cerdo atravesaron por una coyuntura excepcional a lo largo de la década de 197054. Desde 1973 el consumo de carne porcina creció sensiblemente (en un 63\% entre ese año y el de 1979), debido a la caída de las ventas de la de vaca y cordero provocada por la crisis económica ${ }^{55}$.

\footnotetext{
52 AGA, Sindicatos, Sindicato Nacional de Ganadería, legajo 34/6.581.

53 El País, 1-1-2006, Martínez Carrión (2002), p. 503 y (2006), p. 411 y Registro Mercantil de Murcia (RMMU en adelante), hoja 435.

54 Gasóliba (1972).

55 Sobre la relación marginal de sustitución de los productos cárnicos véase Hayes, Ahn y Baumel (1991); Byrne, Capps, Tsai y Williams (1995).
} 
Las salchichas, el chopped y la mortadela ganaron peso en la dieta, en unos años en que los bolsillos de los españoles no daban para demasiadas alegrías. Tal fue la pujanza del sector que las grandes corporaciones trasnacionales, hasta entonces, de espaldas por completo a su desarrollo, depositaron su interés en él. En 1975 la Nestlé se hizo con la segoviana Acueducto y la panameña Beralf con La Piara. El propio INI creyó factible hacer rentables a las empresas cárnicas bajo su órbita, desde 1975 integradas en CARCESA, al rebujo de una situación tan favorable ${ }^{56}$.

Fue Marqués, y no Ballvé, el gran beneficiario del desplazamiento de la demanda de canales. En 1973 integró en la denominada General de Mataderos, S.A., con un capital de 176 millones de pesetas, a Frigorífico Marqués, S.A y a las empresas cárnicas de su suegro, Anselmo Gil Tacons ${ }^{57}$. En 1975 su facturación, en pesetas corrientes, se triplicó, rebasando ampliamente a la de Campofrío.

Marqués no se quedó ahí y abundó en la búsqueda de economías de gama. En 1976 General de Mataderos, S.A firmó un convenio con la estadounidense Oscar Mayer, fundada en 1952. Con arreglo a su tenor, la empresa (ahora denominada OMSA) podría fabricar salchichas alemanas con licencia de Oscar Mayer, a cambio de su entrada en el accionariado, tras una ampliación del capital hasta 400 millones de pesetas, íntegramente suscrita por el nuevo socio $^{58}$. OMSA no sólo satisfizo la demanda de los turistas, difíciles de cubrir con los embutidos españoles, que desconocían por completo. Los nuevos productos, muy competitivos y novedosos, tuvieron una excepcional acogida entre la población española.

Otro tanto sucedió con los de baja gama elaborados por El Pozo. En lo que hace al mercado del chorizo, Industrias Revilla absorbió en 1974 a Refras e Inquimeso ${ }^{59}$. Incluso nació un nuevo procesador industrial en una rama de actividad que, hasta entonces, parecía refractaria a la lógica fabril: Manuel Díaz. Desde 1975, distribuyó jamón curado fileteado y envasado al vacío, obtenido en su secadero de Torrijos (Toledo), bajo la denominación de Navidul ${ }^{60}$.

Entre tanto, Campofrío perdió el dominio que hasta entonces señoreaba (Gráfico 2), por culpa de su escaso grado de integración vertical hacia atrás, una gama petrificada en torno al jamón cocido y una política de dividendos poco congruente con la trayectoria del ciclo (Gráfico 1).

56 Barciela, López y Melgarejo (2004), p. 136.

57 Se tratan de Matadero Industrial de Calamocha, S.A., fundada en 1966 en Teruel, Azúcares y Productos Alimenticios (Valencia, 1958) y Productos Cárnicos El Pino, S.L. (Alicante, 1967). RMV, hoja 451.

58 RMV, hoja 451 y OEPM, marca 815.960. Sobre la utilidad de estas alianzas con firmas foráneas para garantizar la continuidad de las grandes empresas familiares, véase Fernández y Puig (2007).

59 Registro Mercantil de Soria (RMSO en adelante), hoja 30.

60 OEPM, marca 930.749, Registro Mercantil de Madrid (RMM en adelante), tomo 2.268, folio 182, hoja M40.022 y AGA, Industrias, legajo 6.131, expediente 36.400 . 


\section{GRÁFICO 2}

EVOLUCIÓN DE LAS VENTAS DE LAS GRANDES EMPRESAS CÁRNICAS ESPAÑOLAS, 1971-1998 (en términos reales y números índices base 1980)

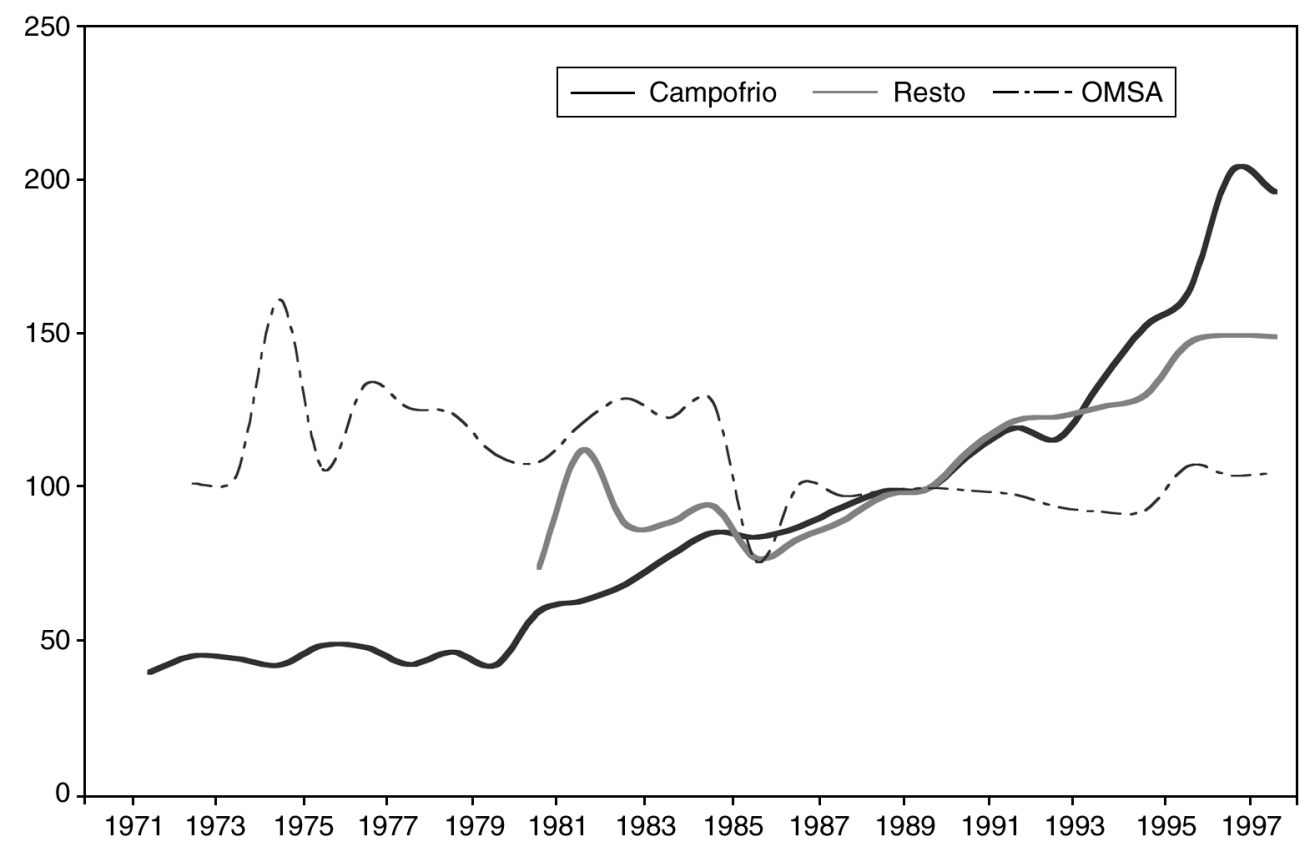

Fuente: Fomento de la Producción (1971-1983), pássim y Publicaciones Alimarket (1984-93) y (1994-2000), pássim. He empleado el deflactor implícito del PIB de Alcaide (2000).

Ballvé tuvo que hacer frente a una severa apreciación de las crías de cerdo. De poco sirvieron las batallas que libró con el FORPA en materia de precios, por más que saldadas con alguna victoria pírrica ${ }^{61}$. No sólo cayeron las ventas de canales en el sudeste de España tras el nacimiento de OMSA, sino también en Lérida (ahora territorio de Industrias Leridanas del Cerdo y Cooperativa Agraria de Guissona) y Gerona (de Matadero General Frigorífico de Binéfar y Frigoríficos del Ter ${ }^{62}$. También menguaron las de productos elaborados, en este caso, debido a la competencia de El Pozo. En circunstancias tan complejas, en 1973 Eguía abandonó la compañía ${ }^{63}$.

AGA, Sindicatos, Sindicato Nacional de Ganadería, legajo 12.671 (acta de la Agrupación de Industrias Cárnicas de 16-VII-1975).

62 Sobre la Cooperativa Agraria de Guissona véase Roca y Roca (2004).

63 RMBU, hoja 462. 
Para evitar, en sus propias palabras, "un suicidio lento, pero irreversible", Ballvé debía atenuar la dependencia en el suministro de animales ${ }^{64}$. Con tal propósito, Campofrió integró verticalmente la cría y engorde de lechones con la creación en 1974 de las empresas filiales Cebaderos Castellanos, Ivanasa, Carneiberia, Campoverde y Degasa, esta última participada por el Ministerio de Agricultura francés.

No menos perentoria era la necesidad de diversificar el producto. Tras un intento, más voluntarioso que eficaz, de incursionar en el mercado del jamón curado, Campofrío buscó el respaldo tecnológico y comercial de una empresa extranjera, tal y como hizo antes General de Mataderos, con este fin ${ }^{65}$. En 1978 Ballvé dio entrada en Campofrío a la cárnica de Chicago Beatrice Foods, mediante una ampliación de capital en 240 millones de pesetas. Ambas firmas, unidas en Interalimen, pasaron también a formar parte del accionariado de Industrias Leridanas del Cerdo y de la lucense Industrias Abella ${ }^{66}$.

De inmediato, Campofrío se embarcó en el lanzamiento de sus salchichas, elaboradas en una planta levantada en Madrid a tal efecto ${ }^{67}$. Ballvé rediseñó la política de distribución para adecuarse a las necesidades de suministro a los nuevos supermercados. Incluso mejoraron sus relaciones con los mandatarios de la CAT. De hecho, llegó a producir jamón destinado a los canales públicos de distribución que ella controlaba.

La empresa pudo, merced a todo ello, mantener sus ingresos de explotación, a diferencia de su principal competidora, OMSA, cuyos resultados en la segunda mitad de la década no fueron particularmente brillantes (Gráfico 2). El reparto implícito del mercado entre las grandes firmas de La Meseta, al que se unió Navidul, funcionó ejemplarmente, en beneficio de Campofrío.

Ballvé participó activamente en la fundación de la Confederación Española de Organizaciones Empresariales, aunque no tuvo en esta institución patronal las responsabilidades arbitrales que ejerció antes en el Sindicato Vertical. Eso sí, el abulense, ya domiciliado en Madrid, se incorporó al Consejo de Administración de grandes empresas aceiteras y vinícolas, tareas que compatibilizó con la gestión de negocios inmobiliarios. Ningún otro empresario cárnico (ni menos aún, castellano) había llegado tan lejos.

\footnotetext{
64 AGA, Sindicatos, Sindicato Nacional de Ganadería, legajo 12.671 (acta de la Agrupación de Industrias Cárnicas de 16-VII-1975).

65 En 1974 firmó un acuerdo con la firma Campoverde de Monforte de Lemos, creó la sociedad Camposierra para comercializar jamón de Jabugo de Aracena y absorbió a las empresas burgalesas Embutidos Ibéricos y Matadero Frigorífico "La Española". Pero el nacimiento de Navidul abortó el intento.

66 Publicaciones Alimarket (1984), p. 85 y RMBU, hoja 462.

67 RMBU, hoja 462 y Cárnica 2.000. 1973-98.25 Aniversario, pássim.
} 


\section{Cambio generacional y turbulencias empresariales, 1983-1989}

En 1983 la peste porcina situó en una posición crítica a las empresas cárnicas españolas (Gráfico 3), en especial OMSA (Cuadro 1). Las familias fundadoras (los Marqués y Gil Tacons) se desvincularon de ella, inmediatamente después del cambio de propiedad del socio de referencia estadounidense, Oscar Mayer, ahora en manos de Phillips Morris, a través de General Foods ${ }^{68}$. Una auténtica letanía de quiebras entre las pequeñas empresas forzó un proceso de concentración horizontal que el propio Gobierno, a través del Plan Indicativo de Mataderos, aprobado en marzo de 1984, incentivó ${ }^{69}$.

Navidul, ahora integrada en el holding Grupo Manuel Díaz, levantó dos plantas más entre 1984 y 1988 en Torrijos y Oria del Rey (Toledo). Emiliano Revilla, adquirió en 1983 las cárnicas nacionalizadas del Grupo Rumasa ${ }^{70}$. La crisis paso de puntillas para Fuertes, al igual que para Casademont, parapetada en la fabricación de embutidos de calidad a los que la mercadotecnia pudo darles una apariencia artesanal. Incluso nació en Cataluña una nueva firma en 1983 siguiendo su estela: Casa Tarradellas $^{71}$.

Campofrío afrontó este nuevo escenario en medio de un cambio generacional realizado sin mayor trauma ni tensión interna. José Luis Ballvé, meses antes de fallecer en noviembre de 1985, cedió la gestión efectiva a su hijo Pedro, mucho más familiarizado con ese entorno competitivo, en tanto que adiestrado en el negocio en Chicago, y desde 1978, responsable de los departamentos de control-calidad y marke$\operatorname{ting}^{72}$.

El nuevo responsable recuperó el aliento innovador de la empresa ${ }^{73}$. A lo largo de 1984 y 1985 desembolsó 1.200 millones de pesetas (equivalentes a un 60\% del capital nominal) en nuevas tecnologías, suficientes para minorar la diferencia de un $10,1 \%$ en la productividad del trabajo que le separaba de OMSA, a causa del crecimiento, un tanto abultado, de la plantilla (más de 1.700 personas), y superar, de nuevo, a su mayor rival (Gráfico 1) ${ }^{74}$.

El crack de la bolsa de Nueva York de octubre de 1987 provocó un terremoto en el sector cárnico español. El broker Reginal Lewis, propietario de KKR, y la alemana Coop. AG desembarcaron en el accionariado de Campofrío y OMSA, respectivamente,

\footnotetext{
68 RMV, hoja 451.

69 El mencionado plan contemplaba reducir los mataderos en activo en el país de 2.064 a 338.

70 RMSO, hojas 30 y 361. La nueva titular inyectó 1.800 millones de pesetas en el capital.

71 RMB, hoja 56.768.

72 Véase Rowe (1976).

73 RMBU, hoja 462.

74 RMBU, hoja 462, Publicaciones Alimarket (1985), p. 71 y Fomento de la Producción (1987), p. 86.
} 


\section{CUADRO 1}

EL REPARTO DEL MERCADO ENTRE LAS PRINCIPALES EMPRESAS ESPAÑOLAS DEDICADAS

A LA FABRICACIÓN DE EMBUTIDOS, 1982-2005

(en porcentajes)

\begin{tabular}{|c|c|c|c|c|c|c|c|c|c|}
\hline 毫 & 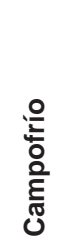 & 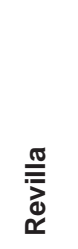 & 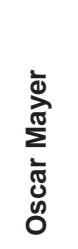 & $\begin{array}{l}\stackrel{\text { N }}{0} \\
\frac{0}{\square} \\
\bar{\Psi}\end{array}$ & $\begin{array}{l}\overline{\bar{z}} \\
\frac{\pi}{\pi} \\
\frac{\pi}{2}\end{array}$ & $\begin{array}{l}\frac{\pi}{\frac{\pi}{\pi}} \\
\frac{\pi}{2} \\
\frac{\pi}{3}\end{array}$ & 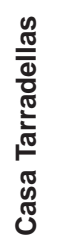 & 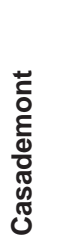 & $\begin{array}{l}\bar{\varpi} \\
\text { 음 }\end{array}$ \\
\hline 1982 & 28,8 & 18,3 & 34,4 & 9,5 & 4,4 & 4,6 & - & - & 100,0 \\
\hline 1987 & 29,4 & 16,1 & 21,3 & 13,8 & 4,5 & 4,7 & 3,0 & 7,1 & 100,0 \\
\hline 1990 & 30,4 & 12,7 & 19,0 & 16,5 & 8,1 & 4,5 & 3,9 & 6,4 & 100,0 \\
\hline 1995 & 37,7 & - & 14,4 & 18,4 & 13,0 & 5,4 & 5,6 & 5,5 & 100,0 \\
\hline 1999 & 46,4 & - & 13,3 & 15,8 & 8,9 & 3,0 & 7,4 & 5,1 & 100,0 \\
\hline 2005 & 47,3 & - & - & 24,5 & - & 2,7 & 22,0 & 3,5 & 100,0 \\
\hline
\end{tabular}

Fuente: Publicaciones Alimarket (1984-1993), (1994-2006) y elaboración propia.

tras adueñarse de las participaciones de Beatrice Foods y de Phillips Morris ${ }^{75}$. Pero, mientras que la Coop. AG pretendía, a priori, diversificar sus negocios en España, donde ya poseía Mantequerías leonesas y Garvey, Lewis no tenía más objetivo que lucrase de una hipotética reventa.

Las amenazas no sólo llegaron del exterior. Otras empresas de la alimentación aprovecharon esta situación de ínterin por la que transitaban las dos firmas para crear en 1987 sus divisiones cárnicas. Tales fueron los casos de Nutrexpa (con La Piara), la Sociedad General Azucarera de España (Pamplonica) y Tabacalera, a través de su filial Royal Brands (CARCESA) ${ }^{76}$. El statu quo entre los productores cárnicos castellanos quebró en 1986, tras la venta de Industrias Revilla a Unilever y Carmusa a Fuertes, inmediata a la liberación de Emiliano Revilla de su secuestro por ETA ${ }^{77}$. Tanto fue así que otro empresario burgalés muy próximo a Ballvé, Tomás Pascual, creó en 1987 su propia filial cárnica, Campocarne.

RMV, hoja 451.

Dehesa (1996) y Comín y Martín Aceña (1999), pp. 541-546.

RMSO, hojas 30 y 361. 


\section{GRÁFICO 3}

RENTABILIDAD DE LAS EMPRESAS CÁRNICAS ESPAÑOLAS, 1981-2006

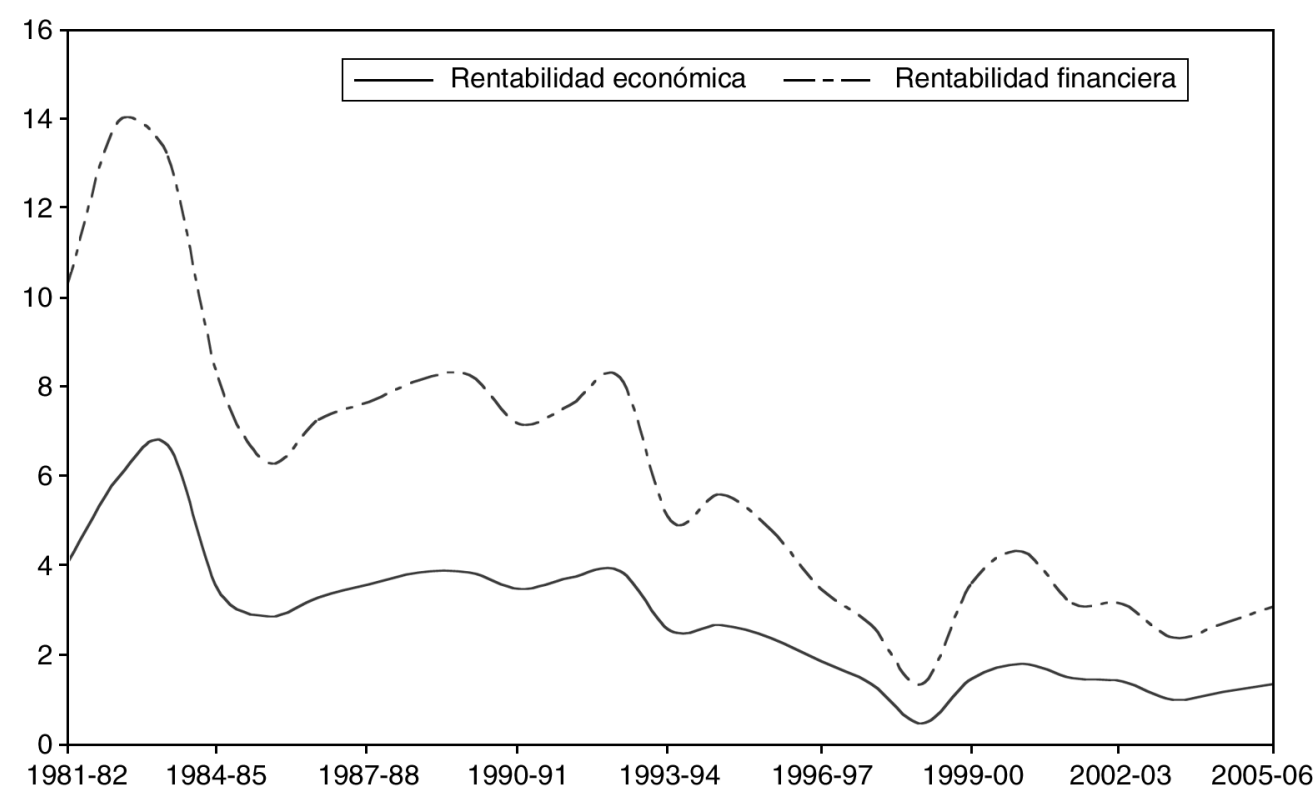

Fuente: CBBE y elaboración propia.

Estas adversidades pusieron a prueba las habilidades directivas de Ballvé, obligado a recabar el auxilio de Alfonso Escámez. El Banco Central prestó los diez mil millones de pesetas que desembolsó en la compra a Lewis de sus derechos en la sociedad. A cambio, la entidad financiera pasó a controlar en 1988 un 25\% del capital, mientras que la familia, a través de la sociedad Grupo Ballvé, poseía el 75\% ${ }^{78}$.

Superada esta situación, Ballvé modernizó el organigrama de la empresa, con la ayuda de los hermanos José Carlos y Aldo Olcese, amigos de la infancia ${ }^{79}$. En 1987 organizó los departamentos de Recursos Humanos, I+D (bajo el nombre de Campotec) y marketing y puso en marcha un plan de formación en el que participó toda la plantilla, en colaboración con el Ministerio de Educación ${ }^{80}$. En mayo de 1988 Campofrío

78 Publicaciones Alimarket (1988), pp. 92-93.

79 Sobre su filosofía gerencial véase Ballvé (1997).

80 Ballvé (1988). 
TABLA 1

EL ENTRAMADO EMPRESARIAL DE CAMPOFRÍO EN 1992

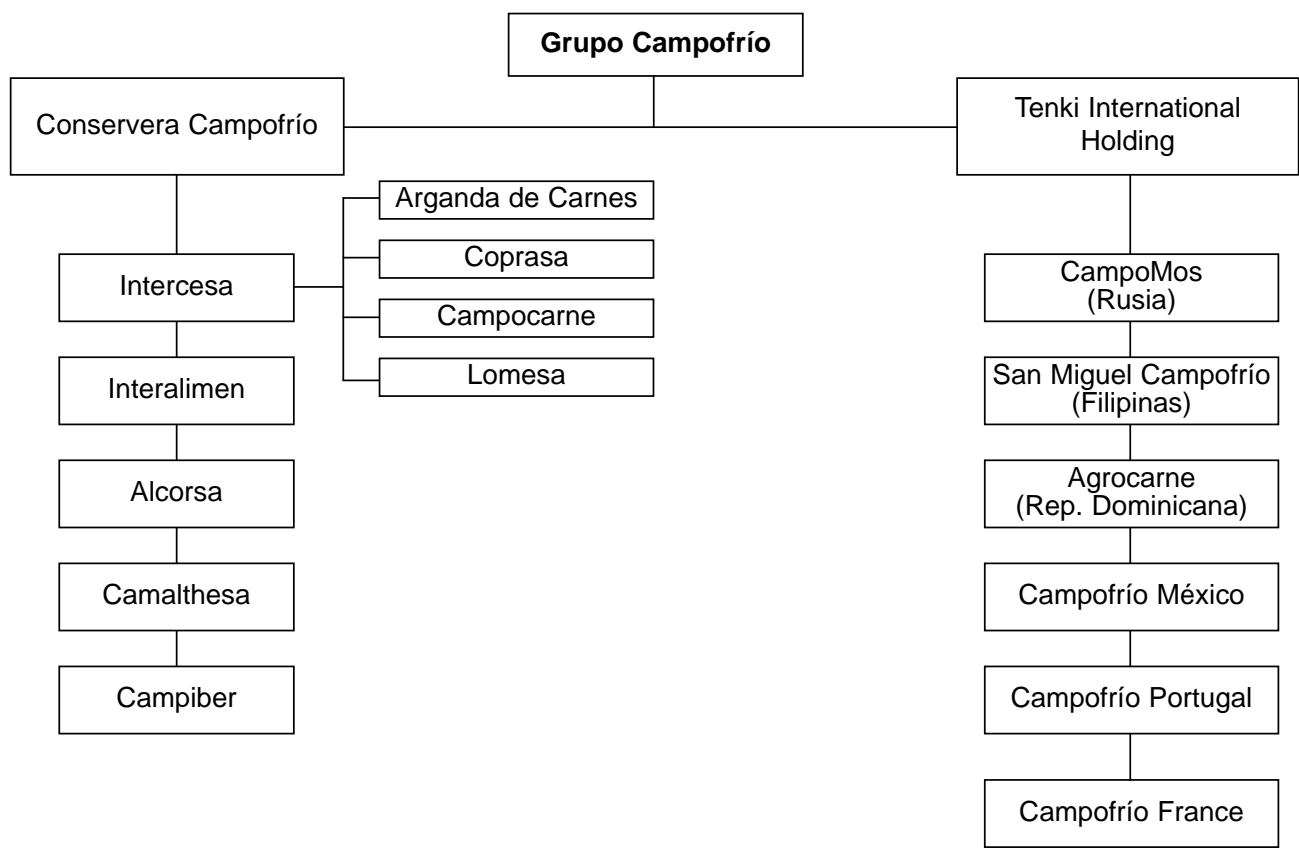

Fuente: Registro Mercantil de Burgos y Publicaciones Alimarket (1993).

comenzó a cotizar en Bolsa. La operación, preparada durante mucho tiempo, supuso la colocación de un tercio del capital en tres años ${ }^{81}$. Tales cambios desembocaron en la formación de Grupo Campofrío, que haría las veces del corporativo donde se integraban todas las empresas de la familia, cuyo capital, patentes y marcas administraba (Tabla 1). En 1990 el domicilio social fue trasladado a Madrid ${ }^{82}$.

Ballvé avanzó en la integración vertical del sacrificio con la absorción en 1989 de Industrias Leridanas del Cerdo. Tras años de cierta atonía inversora, en 1990 fueron inauguradas nuevas plantas en Burgos y en Madrid. Ballvé amplió la gama con la fabricación de conservas de carne de pavo, alimentos para mascotas (por la filial Coprasa) y quesos (por Camalthesa, formada junto con la francesa Perrier) ${ }^{83}$.

\footnotetext{
81 Publicaciones Alimarket (1988), pp. 92-93, (1989), p. 112.

82 RMM, hoja 6204.

83 Publicaciones Alimarket (1990), p. 160.
} 
Pero Ballvé dio prioridad absoluta a la internacionalización de Campofrío, de la mano de la filial instrumental Tenki $B V^{84}$. Europa occidental fue su primer objetivo, una vez incorporado nuestro país a la CEE en 1986 y levantadas en diciembre de ese año las restricciones a la importación de productos cárnicos españoles dictadas por las autoridades comunitarias a causa de la peste porcina ${ }^{85}$. Como primer paso, Ballvé firmó un acuerdo con Manuel Díaz Ruiz, propietario de Navidul, para la comercialización conjunta de jamón serrano en Francia (a través de Sociedad Nuevo Grupo) y Portugal (junto con la lusitana Cárnicas Nobre) ${ }^{86}$.

Simultáneamente Ballvé preparó su irrupción en Rusia y Estados Unidos. En 1989 constituyó en Moscú la empresa CampoMos en compañía de la vernácula Mosmiasoprom ${ }^{87}$. Casi simultáneamente inauguró su planta en la República Dominicana, adscrita a la empresa Agrocarne, formada con la azucarera Central Romana Corp, cuyos productos habría de exportar a Estados Unidos, una vez desechada la idea de instalar un matadero en Minnesota, debido a los elevados costes laborales ${ }^{88}$.

\section{Europa del este en el punto de mira, 1990-1998}

En los primeros años de la década de 1990 Campofrío y sus competidoras obtuvieron unos resultados muy satisfactorios. Mas la recesión de 1993 puso en jaque a un sector que había experimentado en el lustro anterior un crecimiento inversor casi enloquecido. La sobreproducción agudizó la competencia en precio, avivada con particular denuedo por Fuertes, lo que se materializó en un envilecimiento de los resultados empresariales (Gráfico 3) y, en lo que atañe a Campofrío, en una caída de la cotización en Bolsa de sus valores (Gráfico 4). De nuevo, ello provocó una cadena de quiebras y suspensiones de pagos, que afectó ahora con particular dureza a las cárnicas navarras ${ }^{89}$. La situación ahuyentó a los grandes inversores. AG Coop. salió de OMSA, tras ceder sus derechos a Inversiones Iberosuizas. Por su parte, Tabacalera vendió en 1994 Royal Brands, aquejada de idénticos problemas, a la corporación estadounidense Nabisco.

\footnotetext{
84 Ballvé (1992).

85 Beneblas (1987) y Hernández y Paz (1991).

86 RMM, hoja 6204.

87 Publicaciones Alimarket (1990), p. 160.

88 Inicialmente Díaz iba a participar en la empresa; pero se volvió atrás en el último momento. Campofrío ejecutó la inversión con el apoyo financiero de Proteinas, Grasas y Aceites Animales, a cambio de la cesión de un 2,4\% del capital en el corporativo matriz de la firma burgalesa (Publicaciones Alimarket (1990), p. 160).

89 Fosforera Española se hizo cargo de Mina en 1990. El intento de Ramón Fiter Autet de resucitar a Pamplonica y a la Corporación Alimentaria Ibérica, a través de la financiera Fitinvest, resultó un fiasco. Otro tanto sucedió con el grupo Hesperia y Argal, que acabó en manos en 1993 de BP Nutrition, la división cárnica de la estadounidense Sara Lee Baker.
} 


\section{GRÁFICO 4}

COTIZACIÓN MEDIA ANUAL DE LAS ACCIONES DE CAMPOFRÍO, 1998-2008

(en euros corrientes)

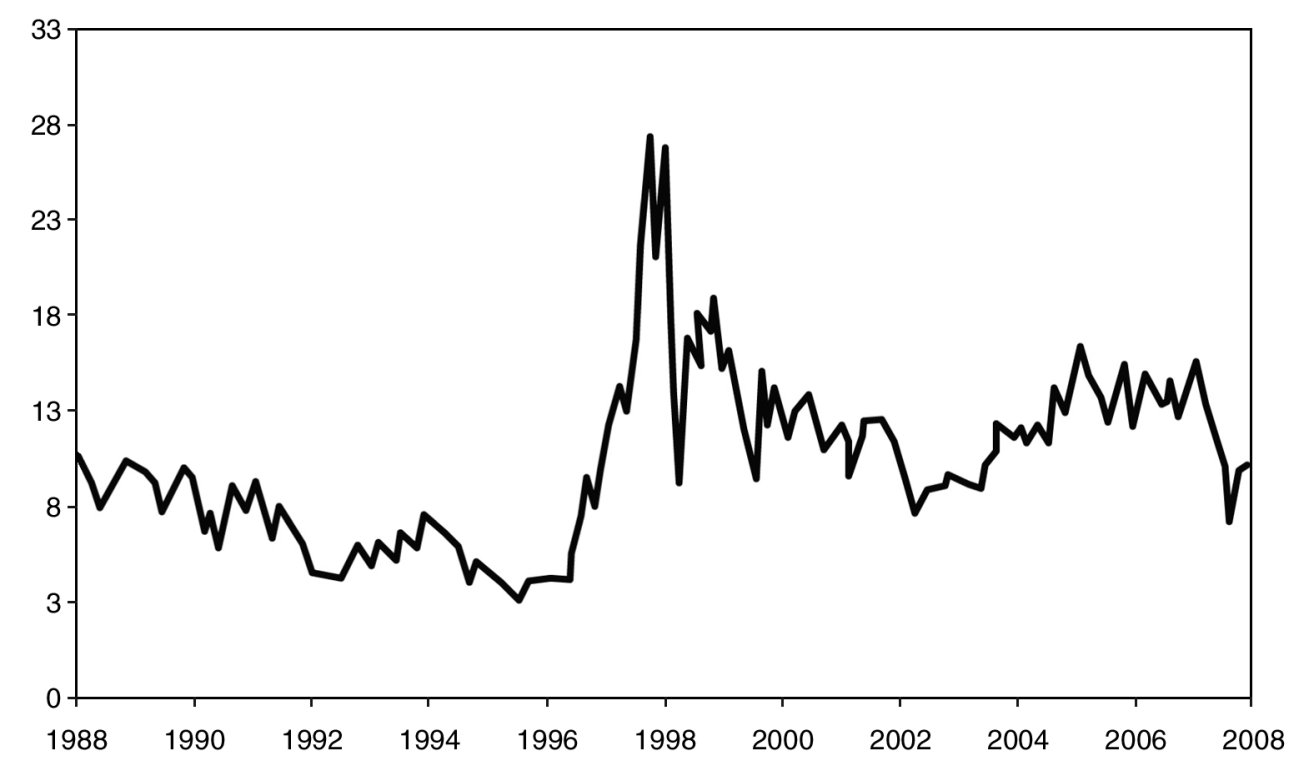

Fuente: Bolsa de Madrid. Elaboración propia.

La coyuntura aconsejaba la formación de un gran grupo que atenuase el descenso de los ingresos de explotación y desactivase la amenaza que representaban las firmas extranjeras, tal y como estaba sucediendo en Italia ${ }^{90}$. Navidul, que había adquirido ya unas dimensiones considerables (tabla 2), tanto más desde la adquisición en 1995 de Revilla, asumió el reto. Juan Abelló, el mayor accionista de Inversiones Ibersuizas (participada en un 7,7\% por Navidul), habría de ejecutar esta fusión, muy bien vista por el Gobierno socialista ${ }^{91}$.

Ajeno a estas contingencias, Ballvé empleó sus energías y los recursos de la empresa en la fundación de dos nuevas filiales en Filipinas (1991) y México (1992) 92. Ballvé obtuvo en Rusia una recompensa casi inmediata a su resolución (Cuadro 1).

\footnotetext{
90 Mora y Menozzi (2005).

91 Publicaciones Alimarket (1989), p. 112, RMSO, hoja 30 y RMV, hoja 11.257.

92 Es más, Ballvé rompió en 1991 el acuerdo que tenía firmado con Navidul para producir jamón en Francia.
} 
TABLA 2

EL ENTRAMADO EMPRESARIAL DE NAVIDUL EN 1990

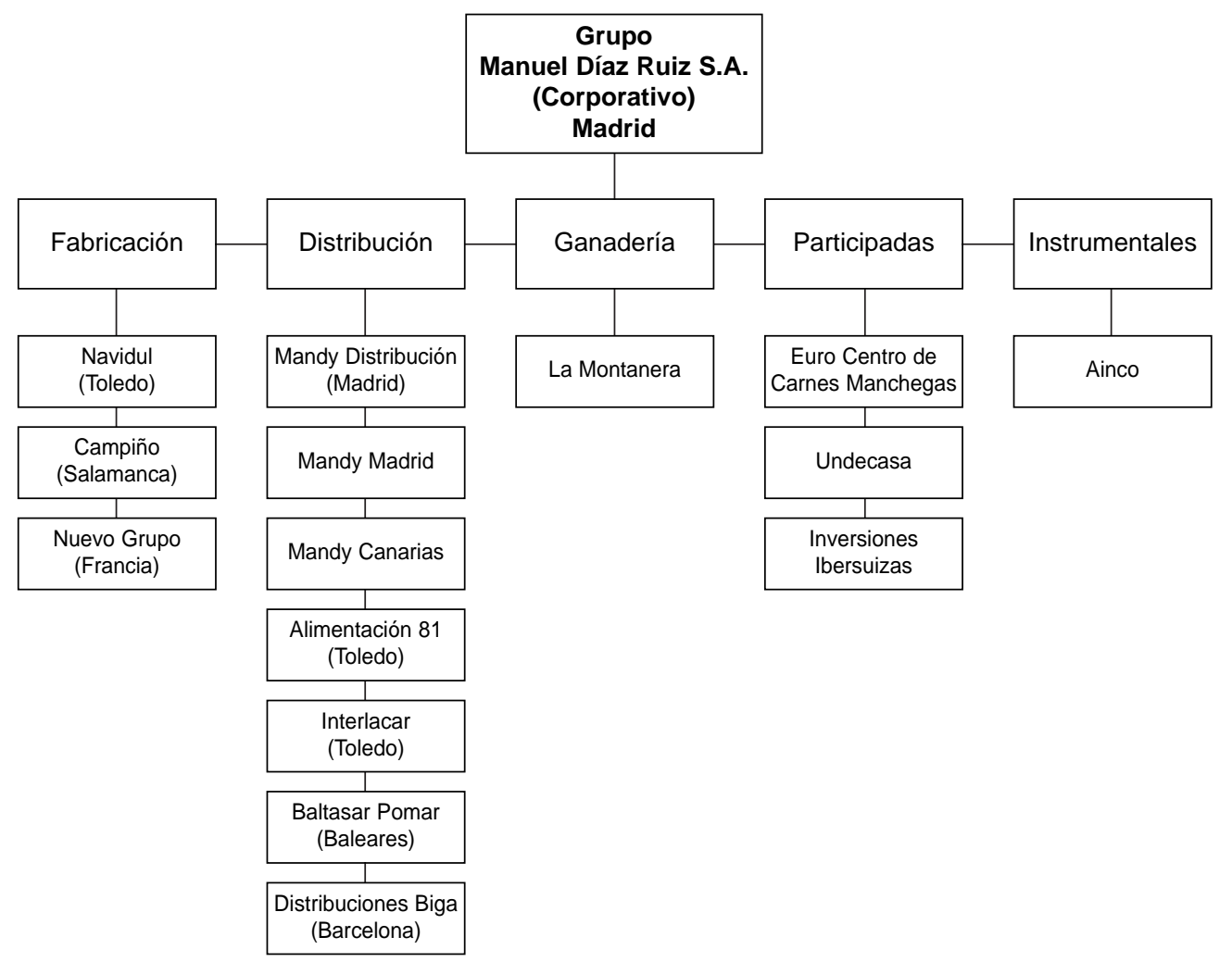

Fuente: Publicaciones Alimarket (1991).

Incluso inauguró una nueva fábrica en Ochacovo en abril de 1994 y creó dos nuevas empresas distribuidoras, CampoImport y Toreador ${ }^{93}$. Pero esta apuesta por su división exterior tuvo funestas consecuencias para la compañía en el medio plazo. La crisis económica mexicana de 1994 acabó por malograr su proyecto de establecerse en ese país y, lo que es peor, provocó un severo descenso de los beneficios de la matriz (Gráfico 5).

93 Publicaciones Alimarket (1992), p. 94 y (1996), p. 90. 


\section{CUADRO 2}

RESULTADOS NETOS DE LAS DIVISIONES DE CAMPOFRÍO EN EL EXTERIOR (1993-2005)

(en miles de euros corrientes)

\begin{tabular}{rrrrrrrr}
\hline AÑO & RUSIA & $\begin{array}{c}\text { HISPANO- } \\
\text { AMÉRICA }\end{array}$ & FILIPINAS & $\begin{array}{c}\text { ESTADOS } \\
\text { UNIDOS }\end{array}$ & $\begin{array}{c}\text { EUROPA } \\
\text { OCCIDENTAL }\end{array}$ & $\begin{array}{c}\text { EUROPA } \\
\text { DEL ESTE }\end{array}$ & TOTAL(*) \\
\hline $\mathbf{1 9 9 3}$ & 872 & -6.879 & -1.687 & - & -283 & - & -7.978 \\
$\mathbf{1 9 9 4}$ & 753 & -7.584 & -3.592 & - & 234 & - & -10.190 \\
$\mathbf{1 9 9 5}$ & 6.631 & -8.458 & -3.859 & - & -2.077 & - & -7.762 \\
$\mathbf{1 9 9 6}$ & 17.565 & -2.116 & -1.818 & - & -2.725 & - & 10.905 \\
$\mathbf{1 9 9 7}$ & 23.367 & -2.289 & -916 & - & -2.749 & - & 17.413 \\
$\mathbf{1 9 9 8}$ & 11.082 & -6.251 & 13 & - & -3.665 & - & 1.180 \\
$\mathbf{1 9 9 9}$ & -5.364 & -4.022 & -1.167 & 296 & -1.174 & -740 & -12.170 \\
$\mathbf{2 0 0 0}$ & -1.695 & -5.989 & - & -1.846 & -4.856 & 709 & -13.678 \\
$\mathbf{2 0 0 1}$ & 12.844 & - & - & 182 & -3.810 & -881 & 8.335 \\
$\mathbf{2 0 0 2}$ & 16.260 & - & - & 507 & -6.628 & 202 & 10.341 \\
$\mathbf{2 0 0 3}$ & 6.424 & - & - & 619 & 968 & 1.649 & 9.806 \\
$\mathbf{2 0 0 4}$ & -484 & - & - & 487 & -788 & 1.090 & 551 \\
$\mathbf{2 0 0 5}$ & -8.082 & - & - & - & -2.068 & 2.983 & -7.097 \\
\hline
\end{tabular}

(*): Desde 2002 incluye los resultados de Campofrío International Finance S.A.R.L.

Fuente: CNMV, Campofrío Alimentación, Cuentas Anuales e informes de gestión (1993-2002), Campofrío Alimentación (2002-2006), pássim y elaboración propia.

El revés no pudo llegar en peor momento. En marzo de 1996 fueron detectados los primeros casos de "vacas locas" en España. El sector perdió su, ya de suyo, menguado atractivo. Juan Abelló se desprendió de su participación en OMSA (equivalente a un $25 \%$ del total) en favor de Fomento de Construcciones y Contratas ${ }^{94}$. Con su espantada y el cambio de Gobierno, el proyecto de fusión con Navidul quedó desterrado. Casi simultáneamente, el Banco Central vendió la suya en Campofrío, con el consentimiento de Ballvé, a la estadounidense Hormel Foods ${ }^{95}$.

Ballvé elaboró entonces un nuevo plan estratégico que contempló una simplificación de la estructura de gestión y de la gama de productos, la informatización de

94 Publicaciones Alimarket (1996), p. 64.
95 La empresa fue fundada en 1891 en Austin por unos emigrantes alemanes. 


\section{GRÁFICO 5}

LA RENTABILIDAD ECONÓMICA DE LAS EMPRESAS DE LA FAMILIA BALLVÉ, 1994-2005

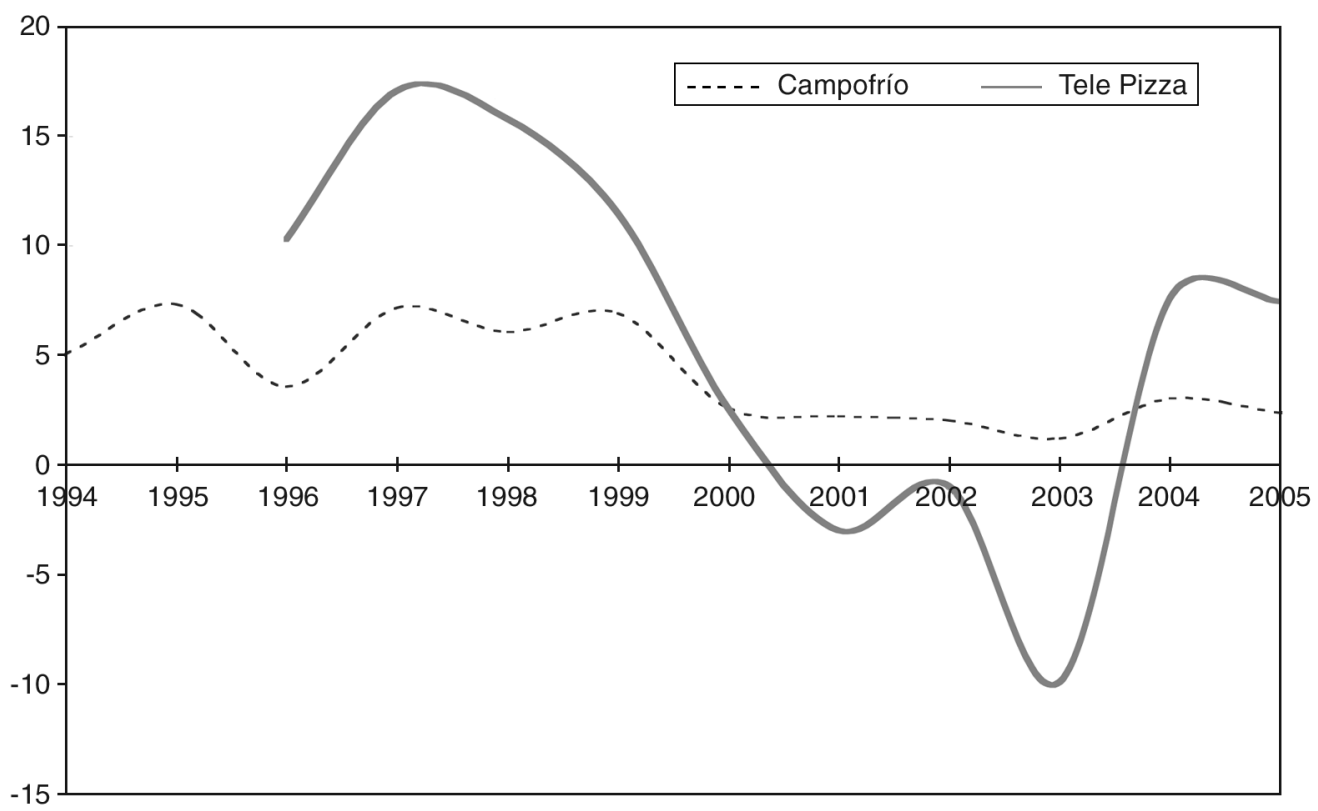

Fuentes: Las detalladas en el Cuadro 2, CNMV, Tele Pizza, cuentas anuales e informes de gestión (1996-2005) y elaboración propia.

los procesos de fabricación, la subcontratación de la distribución y, sobre todo, la consecución de mayor independencia en el suministro de crías ${ }^{96}$.

Ante las pésimas perspectivas en el mercado interno, Ballvé dio un nuevo impulso a la internacionalización del grupo. En 1996 Campofrío se estableció en Argentina y en Bolivia. Mas la crisis asiática de 1997, contagiada a América Latina, desbarató sus planes. Las legaciones de ambos países y de la República Dominicana fueron clausuradas ${ }^{97}$. Desde entonces, del mercado estadounidense se ocupó una

96 Ballvé relanzó la venta de canales, con la creación de una nueva empresa ganadera (Campobeef), junto con la británica JRS y la ONCE, así como la adquisición de los mataderos de Campocarne y el de Los Quijales en Lorca (Comisión Nacional del Mercado de Valores (CNMV en adelante), Campofrío Alimentación, Cuentas anuales e informes de gestión, 1993-1996).

97 Ballvé tuvo que olvidarse también de su pretensión de establecerse en Taiwán. 
fábrica propia en Nueva Jersey adquirida a la Abuin Packing, que elaboraba embutidos bajo la denominación de "El Miño"98.

Tras el traspiés americano, Campofrío acometió su extensión en Europa del Este. En febrero de 1998 se hizo con un 56\% de la rumana Tabco. Poco después, compró la mayor empresa cárnica polaca, la Morliny, al banco alemán Rebobank y al grupo $\mathrm{PBK}^{99}$. Ballvé puso también su empeño en reanimar a la división de Campofrío en la Europa comunitaria, hasta entonces, ruinosa. En 1999 incorporó al grupo a Gayraud Montagne Noire Pyrénées S.A., líder en la fabricación de salchichón en Francia, y a la portuguesa Fricarnes ${ }^{100}$. Por otra parte, firmó varios convenios con las cadenas de supermercados británicas Asda y Waitrose para la distribución de bacon.

Entre tanto, Ballvé, miembro de los Consejos de Administración de Telefónica, Bodegas y Bebidas, González Byass, BCH y Puig Beauty \& Fashion Group, así como accionista de El Mundo, se distanció del mercado interno. Para entonces era el único empresario español componente de la Trilateral, prueba del enorme prestigio adquirido en el exterior. Incluso fue reclamado por el Gobierno en 1997 para la redacción del Código Ético de los Consejos de Administración ${ }^{101}$. Pero el más distinguido miembro de lo que la prensa bautizó cómo la beautiful burgalesa ya no ejercía de interlocutor del lobby cárnico, tarea desempeñada ahora por el diputado convergente Jesús Casedemont.

De hecho, la familia se comprometió en otras aventuras empresariales en la fabricación y venta de pizzas. En 1999, tras fracasar con la firma TeleChef, los Ballvé adquirieron, junto con Gustavo Durán y los Olcese, a Leopoldo Fernández Pujals sus acciones en Tele Pizza, de cuya presidencia se hizo cargo Pedro Ballvé. La extensión geográfica de su división exterior era prácticamente idéntica a la de Campofrío. Incluso Ballvé hermanó aún más a ambas firmas con la creación de una filial de Tele Pizza en Polonia; aunque, eso sí, también tuvo que liquidar la de México.

A juzgar por los datos representados en los gráficos 4 y 5, Campofrío acertó en esa prioridad por el exterior, en unos momentos en que sus competidoras enfrentaban una caída de sus beneficios (Gráfico 3). Sin embargo, el mercado ruso trajo nuevos e inopinados sobresaltos en 1999 (Cuadro 2), causados por la volatilidad del rublo, provocando un cambio de tendencia, justamente cuando la situación mejoraba para el resto ${ }^{102}$. Campofrío no podía seguir de espaldas a España.

\footnotetext{
$98 \quad$ Publicaciones Alimarket (2000), p. 105.

99 Yoruk (2001). Ambas proporcionaron utilidades desde el primer ejercicio (Grupo Campofrío (1999), p.45).

100 Grupo Campofrío (2000), p. 39.

101 Vicent (2003), p. 3.

102 Hormel Foods (1999).
} 


\section{La huida hacia adelante, 1999-2008}

Fue el suyo un retorno complicado. El Pozo pisaba los talones a la primera cárnica nacional (Gráfico 6). No menos llamativo fue el crecimiento de la Cooperativa Agrícola de Guissona, desde 1999 un holding que integraba los negocios cárnicos, la venta al detall, la fabricación de piensos y el crédito ${ }^{103}$.

Es más, sobre Campofrío se cernía otra amenaza potencial derivada de las dificultades por las que estaba atravesando OMSA, lastrada por un continuo baile de accionistas. El intento de Fomento de Construcciones y Contratas de poner fin al calvario de la valenciana resultó en vano. En 1999 negoció su venta a la Smithfield Food Corp, la mayor de las cárnicas de Estados Unidos, entonces en plena expansión en Europa ${ }^{104}$. Ballvé no tuvo pues más alternativa que anticiparse a la Smithfield y lanzar, con el visto bueno de Oscar Mayer, en mayo de 2000 una OPA sobre OMSA, en la que consiguió captar un $87,07 \%$ del capital ${ }^{105}$.

Ahora le correspondía a Ballvé la misión de forzar una concentración en el sector en la que Abelló había fracasado, impelido por las apetencias de la Smithfield. En junio de ese año Campofrío absorbió Navidul. La cesión a Manuel Díaz de un 16\% de su capital, valorado en 14.400 millones de pesetas, y de responsabilidades de gestión en Campofrío, así como el mantenimiento de la identidad y marcas de Navidul, allanaron el camino hacia el acuerdo entre las dos familias ${ }^{106}$.

A priori, Campofrío salió extraordinariamente fortalecida en tanto que pasó a ostentar un dominio absoluto en los todos los segmentos, tanto de carnes en canal como de embutidos. La empresa consolidó también su posición en los mercados exteriores, sobre todo en los norteamericanos, dado que desde 1996 Navidul era la única empresa autorizada por el Departamento de Agricultura a vender jamón serrano en Estados Unidos.

Pero no tardaron en manifestarse los costes de una formación tan repentina de este gigante alimentario, construido sobre cimientos muy frágiles. Los 36 millones largos de euros captados en las ampliaciones de capital de octubre de 2000 y abril de 2002 no bastaron para financiar ambas operaciones y liquidar las deudas de Navidul, por lo que, en ese lapso, se multiplicó por 30 su endeudamiento a largo plazo ${ }^{107}$. Por otra parte, Campofrío tenía que reordenar un entramado empresarial compuesto por

\footnotetext{
103 Roca y Roca (2004).

104 Véase Smithfield Food Inc. (2002b-2004b) y (2007) y Pope (2007a) y (2007b).

105 RMV, hoja 11.257, RMM, hoja 6.204 y Campofrío Alimentación (2003), pp. 89-90.

106 Publicaciones Alimarket (2000), p. 169.

107 Publicaciones Alimarket (2001), pp. 75 y 169, (2002), p. 92 y (2003), pp. 90 y 131 y Campofrío Alimentación (2000) y (2002b).
} 


\section{GRÁFICO 6}

BENEFICIOS DE LAS PRINCIPALES EMPRESAS CÁRNICAS ESPAÑOLAS, 1988-2005

(en millones de pesetas corrientes)

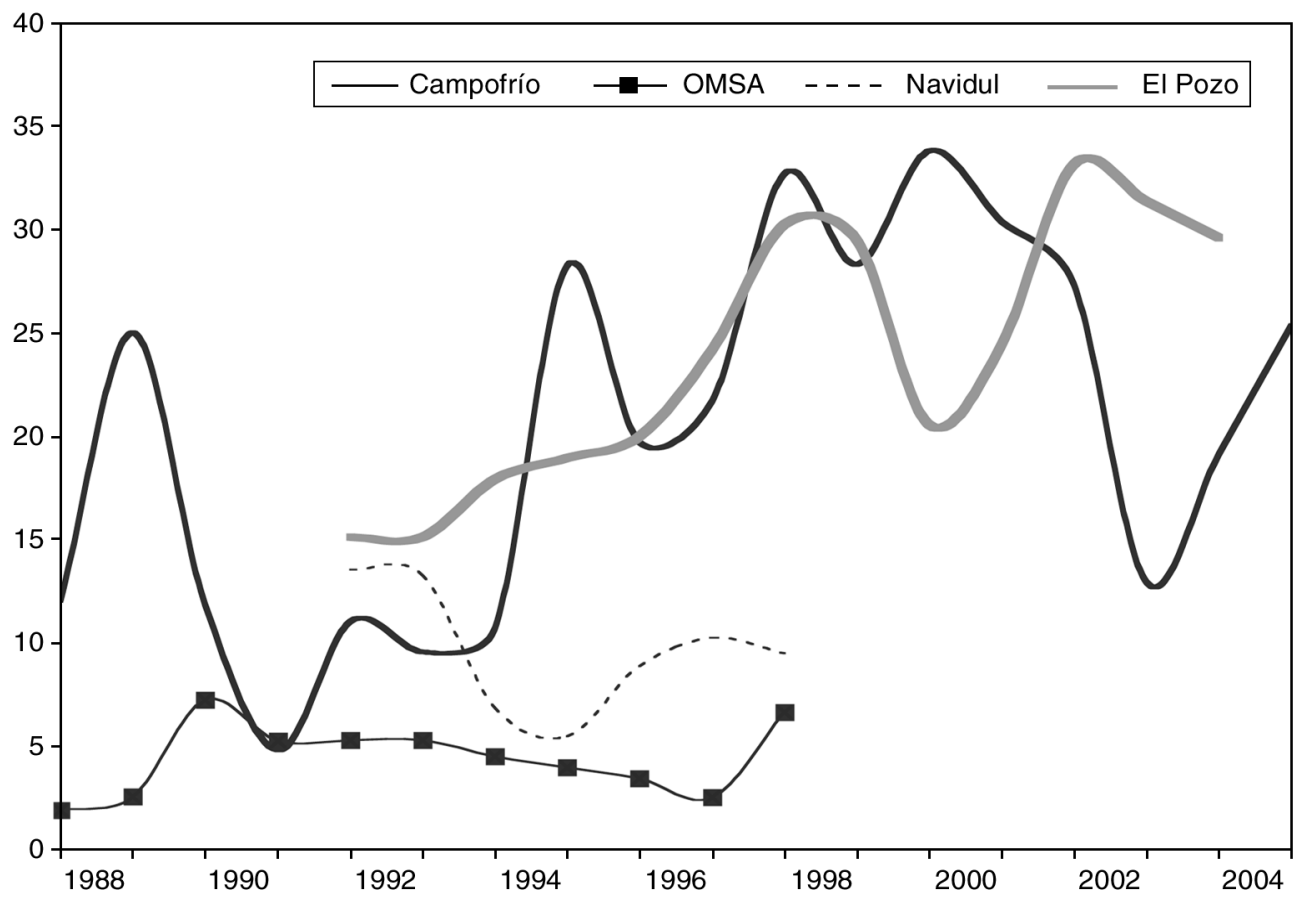

Fuente: Publicaciones Alimarket (1988-93) y (1994-2006), pássim y elaboración propia.

cuatro decenas de firmas, con una plantilla superior a las 10.000 personas y una actividad muy solapada, tanto en España como en el exterior. Para colmo de males, Tele Pizza entró en perdidas, a causa de las secuelas financieras del 11 de septiembre (Gráfico 5).

En aplicación del plan estratégico para el período 2002-2005, redactado, entre otros, por Guillermo de la Dehesa, Campofrío cedió en 2003 todos sus mataderos a Proinserga Inversiones, S.A., una empresa cooperativa de ganaderos segoviana. Aquejada de una onerosa sobrecapacidad productiva, Campofrío procedió al cierre de buena parte de las plantas de despiece y fabricación (pasaron de 44 en 2002 a 13 en 2005). Eso sí la empresa abrió una nueva línea de negocio: la venta de merluza congelada de Namibia, junto con la armadora Mascato, D.L. ${ }^{108}$. 
El plan contempló asimismo la reestructuración de la división exterior del grupo. En 2002 fueron fusionados los negocios de las tres firmas en Francia, Portugal y Estados Unidos, en este caso, en la razón social 814 American Inc ${ }^{109}$. Campofrío se deshizo en 2000 de su participación en la filipina San Miguel Corp. ${ }^{110}$. La crisis económica de 2001-02 precipitó el abandono de las empresas argentinas y brasileñas heredadas de Navidul, desinversiones que tuvieron una amplia repercusión en los mercados de capitales occidentales ${ }^{111}$. Desde entonces, Campofrío exportó a la América hispana productos elaborados en España a través de la subsidiaria Sandrigde Trading Ltd.

Las esperanzas de la empresa estaban depositadas en la Europa del Este y Rusia $^{112}$. Ballvé aportó nuevos recursos a la firma Desarrollo Ganadero Rumano, dedicada a proveer a Tabco. Es más, convencido de las enormes posibilidades del mercado ruso, en 2002 proyectó la construcción en ese país de sendas fábricas de yogures y de café junto con Leche Pascual y la palentina Seda Solubles ${ }^{113}$.

Los frutos efectivos del plan distaron de los esperados en España, donde no registró un incremento significativo de la cuota de mercado (Cuadro 1). Mientras los gestores de Campofrío se quebraban la cabeza tratando de racionalizar la explotación de sus unidades productivas, El Pozo concentró todo su esfuerzo inversor en Alahama de Murcia donde en 2004 explotaba ya un complejo fabril de enormes dimensiones ${ }^{114}$. En 2001 los hermanos José, Tomás y Juana Fuertes Fernández aglutinaron en el Grupo Corporativo Fuertes, S.L. un conjunto de empresas vinculadas a negocios tan diversos como lucrativos (Anexo 2). No menos apreciable fue el crecimiento de las firmas catalanas (Cuadro 1). El Gobierno foral promovió en 2002 la integración de todas las cárnicas navarras en Pamplonica, salvo de Argal, rescatada por un grupo de empresarios catalanes agrupados en Holding Participaciones Cárnicas ${ }^{115}$. Incluso irrumpió en el sector una gran corporación agroalimentaria, Agrolimen, tras hacerse con el Consorcio de Jabugo.

Las cosas no iban mucho mejor en el exterior. De nuevo, El Pozo le cerró el paso de Europa occidental, tejiendo una estructura comercial capaz de llegar con sus productos a 50.000 minoristas de 15 países ${ }^{116}$. Campofrío quedó literalmente arrinconada

Publicaciones Alimarket (2001), p.76. En lo que se refiere a Francia, puso en marcha en 2002 una fábrica, junto con la cooperativa Lur Berri de jamón cocido con denominación de origen "Bayona".

110 Publicaciones Alimarket (2004), p. 181.

111 United Nations Conference on Trade and Development (2002), p. 63.

Publicaciones Alimarket (2004), p. 100 y Ballvé (1998).

Sobre la relación inversa entre tamaño de planta de las cárnicas y costes de producción véase Ward (1993) y Fisher, Noack y Pfeil (1974).

115 Publicaciones Alimarket (2003), p. 213 y (2005), p. 111 y Registro Mercantil de Navarra (RMN en adelante), tomos 595, hoja 4182, 216, hoja 6.935 y 247 y hoja 2.802.

116 Publicaciones Alimarket (2005), p. 111. 
en Rumanía, Polonia y Rusia, sostén de la división exterior del grupo. Bastó el deterioro de los resultados en este país en 2004 (Cuadro 2) para desbaratar las inversiones conjuntas con Pascual y Seda, y lo que es más grave, desatar una tormenta en el propio seno del accionariado, azuzada por la Smithfield Food Corp.

Los mediocres resultados obtenidos (Gráfico 5) y la caída de los dividendos en 2003 acabaron por precipitar la salida de la Hormel de Campofrío ${ }^{117}$. En febrero de 2004 vendió su participación a la Smithfield Food Corp en 49 millones de dólares, con unas plusvalías del 12,2\% ${ }^{118}$. Poco después, Carmen y Maria José Ballvé se desprendieron de sus acciones en favor de fondos de inversión irlandeses y de las Islas Caimán ${ }^{119}$.

A Campofrío le esperaban tiempos de errática dirección y de debilitamiento. Pedro Ballvé tenía sentado al enemigo en su mesa, por más que asegurase que se trataba de un "inversor pasivo". A lo largo de 2004, mediante compras en Bolsa, cifradas en 89 millones de dólares, la Smithfield consiguió incrementar hasta en 22\% su participación en la empresa, aproximándose al 30\% que le permitiría lanzar una OPA por el conjunto del capital. Desde esa posición materializó un acuerdo inaudito: la adquisición de la 814 Americas Inc. y la Morlany ${ }^{120}$. En pocos meses, Ballvé perdió pues sus filiales en Estados Unidos y Polonia y el pleno control de la matriz. A los ojos de los inversionistas, la banca y de la propia Administración Campofrío era una empresa herida.

Estas ventas no saciaron a la Smithfield, en tanto que Campofrío todavía obstaculizaba su extensión en el este de Europa. Los Ballvé, temiendo lo peor, se aferraron a su posición en Tele Pizza, superado el bache por el que atravesó (Gráfico 5).

De nuevo, la caída de los ingresos en Rusia en 2006 ensombreció el futuro de Campofrío. Sus acciones se desplomaron, tras colocar las que conservaba en cartera el BSCH, hasta entonces, aliado en la sombra de Ballvé (Gráfico 4). Entre tanto, la Smithfield acrecentó su presencia en Europa con la firma de una joint venture en agosto de ese año con Oaktree Capital Management LLC para hacerse con los activos en el Continente de la Sara Lee Baker ${ }^{121}$.

Mientras Ballvé, en medio de vitriólicas tensiones gerenciales, capeaba las embestidas de la Smithfield, salió a escena la familia Fuertes, cuyos miembros habían comprado en pequeñas y discretas operaciones acciones de Campofrío, hasta sumar en 2007 un 3\% de su capital. Ello aconsejó a Ballvé a abandonar su estrategia de enfrentamiento y a negociar con la Smithfield, en tanto que no estaba en condiciones de combatir en dos frentes.

\footnotetext{
117 Hormel Foods (2004).

118 Smithfield Foods Inc. (2007).

119 Campofrío Alimentación (2004), p. 14 y (2004b), pp. 48-50.

120 Campofrío Alimentación (2004), p. 14 y (2005), p. 15; Smith Field Foods Inc. (2005b) y (2007), pássim.

121 Smith Field Foods Inc. (2006), p. 7.
} 
El acuerdo se materializó en el muy corto plazo. En junio de 2008 ambas empresas comunicaron la fusión de Campofrío y la división europea de la Smithfield, a la que le correspondió un $51 \%$ del capital en la nueva firma. La burgalesa (la entidad absorbente) asumió nuevas atribuciones en la esfera de la distribución en el conjunto de Europa, una vez enajenada su división en Rusia.

Por más los Ballvé perdiesen peso en el accionariado, el acuerdo, saludado por los mercados bursátiles de Estados Unidos y España, así como por el propio Gobierno, resultó muy favorable para la familia y para el propio sector. De resultas de él, nació una gran corporación hispano-estadounidense que alardeaba de una hegemonía incontestable en la producción y distribución de productos cárnicos en Europa.

\section{Conclusiones}

Campofrío, una compañía familiar castellana con mera proyección local en sus inicios, mudó en sólo media centuria, en la mayor empresa cárnica de España y la más potente de Europa en el cambio de siglo. Y ello a pesar de la actitud beligerante que mantuvieron hacia ella, como poco hasta 1965, los poderes públicos (particularmente, el INI y la CAT) y de una ordenación del mercado cárnico vigente hasta 1986 que no favoreció en absoluto la concentración horizontal.

Una de las claves de su éxito descansa en la placidez con la que se efectuó el cambio generacional, lamentablemente poco común en las firmas españolas, dado que, desde el primer momento hubo una nítida distinción entre familia y empresa.

Sus virtudes gerenciales tuvieron una importancia no menor. Campofrío fue pionera en la incorporación del fordismo en las relaciones laborales, la división multifuncional y la planificación estratégica así como en constitución de un departamento de I+D en las empresas alimentarias españolas.

Mediante alianzas con grandes empresas cárnicas estadounidenses, Campofrío pudo adoptar la producción en masa y las economías de escala en un sector no muy permisivo para ello, debido a la extraordinaria diversidad de productos demandados por los españoles.

La estrategia de Campofrío sirvió para poner fin a la fuerte atomización de la industria cárnica, aglutinando en torno a sí a las mayores firmas del país. Tal fue el resultado, en el largo plazo, de la política de acuerdo y no colusión con las competidoras (especialmente, con las de La Meseta) y con las suministradoras instrumentada por Campofrío desde sus orígenes, así como de la formalización de fusiones amistosas. Es más, el relato de la historia de Campofrío desvela la existencia de una comunidad de intereses entre las grandes firmas castellanas y leonesas. 
Campofrío abrió la senda a otras empresas españolas de la alimentación en los mercados de la Europa del Este y en Rusia, muy rentables, aunque erráticos e inseguros. En ellos hizo valer su experiencia en mercados emergentes en procesos de desregulación, cuyos consumidores trataban de emular los hábitos de consumo occidentales: la adquirida en España en los años del Desarrollismo.

No obstante, no está de más insistir en que Campofrío debe su nacimiento a la caprichosa decisión del Gobierno. La firma pertenece a esa generación de empresas alimentadas en la incubadora autárquica, a costa del progreso de otras mucho mejor situadas (en este caso, las catalanas).

Campofrío pagó durante lustro el precio de una baja productividad, ocasionada por el mantenimiento de una plantilla sobredimensionada. A ello se unieron los costes de la infrautilización y dispersión de sus unidades productivas, de resultas de una política de crecimiento mediante absorciones apresurada, si no improvisada.

Campofrío fracasó también en su extensión en América Latina, lo que desmiente esa hipotética perseverancia de las firmas españolas en el Nuevo Continente, aparentemente reacias a abandonar esos mercados en épocas de crisis. Campofrío no lo fue, por lo que su consideración pondera en sus justos términos los logros en el exterior de las firmas españolas.

Campofrío no tuvo mucha fortuna en la elección de sus socios extranjeros. La Beatrice Foods, primero, y la Hormel, después, expusieron a la empresa a turbulencias financieras que le eran ajenas y sembraron una incertidumbre sobre su continuidad solo despejada en 2008.

A pesar de las cautelas del fundador, las tensiones familiares acabaron aflorando. Campofrío no fue, en absoluto, una excepción en esa difícil coexistencia de familia y corporación tan propia de la praxis de la empresa española, en particular, de la castellana.

Con todo, la consideración de Campofrío, con sus debilidades y carencias, contribuye al conocimiento más ponderado del que fue uno de los cambios institucionales de mayor alcance experimentado por la economía española en las dos últimas décadas del siglo XX; esto es, la formación de la gran empresa.

\section{Fuentes}

Archivo General de la Administración (AGA)

Nuevas Industrias

Sindicato Nacional de la Ganadería

Archivo Histórico Provincial de Burgos (AHPB)

Hacienda

Abastos 
Bolsa de Madrid (BM).

Central de Balances del Banco de España (CBBE)

Comisión Nacional del Mercado de Valores (CNMV)

Cuentas anuales e informes de gestión

Oficina Española de Patentes y Marcas (OEPM)

Registro Mercantil de Barcelona (RMB)

Registro Mercantil de Burgos (RMBU)

Registro Mercantil de Girona (RMGI)

Registro Mercantil de Madrid (RMM)

Registro Mercantil de Murcia (RMMU)

Registro Mercantil de Navarra (RMN)

Registro Mercantil de Soria (RMSO)

Registro Mercantil de Valencia (RMV)

\section{Bibliografía}

ALCAIDE INCHAUSTI, Julio (2000): "Series históricas españolas. 1898 a 1998", en VELARDE FUERTES, Juan (coord.), 1900-2000. Historia de un esfuerzo colectivo. Cómo España superó el pesimismo y la pobreza, Madrid, Fundación BSCH/Planeta, Vol. II, pp. 645-712.

ALEMANY Y TORRES, Francisco (1966): Las industrias de la carne y el desarrollo económico y social, Madrid, Grupo de Industrias de la Carne del Sindicato Nacional de Ganadería.

AZZAM, Azzeddine M. y ANDERSON, Dale G., (1996): Assessing competition en meatpacking: Economic History, theory and evidence, Washington, United States Department of Agriculture.

BALLVÉ LANTERO, Pedro (1988): “La formación en la empresa española”, Boletín del Círculo de Empresarios, (41), pp. 171-177.

—(1992): "La internacionalización de la empresa", Revista de Estudios Agrosociales, (161), pp. 323-337.

—(1997): “Consejos de Administración en la empresa familiar", Boletín del Círculo de Empresarios, (62), pp. 133-152.

-(1998): "Rusia: Un país emergente y oportunidades para la empresa española", Economistas, XVI, (76), pp. 70-71.

BARCIELA LÓPEZ, Carlos, LÓPEZ ORTIZ, Inmaculada y MELGAREJO, Joaquín (2002): "La política industrial del franquismo en el sector de la alimentación", en BARCIELA, Carlos y Di VITTORIO, Antonio (eds.), Las industrias agroalimentarias en España durante los siglos XIX y XX, Alicante, Publicaciones de la Universidad de Alicante, pp. 83-101. 
-(2004): “La intervención del Estado en la industria de la alimentación durante el franquismo", Revista de Historia Industrial, (25), pp. 127-162.

BELLO GUTIÉRREZ, José (1997): Embutidos de Navarra, Oria, Sociedad Navarra de Estudios Gastronómicos.

BENEBLAS, León (1987) (dir.): La producció de carn a Catalunya i a la CEE; Estudi comparatiu dels preus, la producció, els costos, la reglamentació $i$ el comportament dels agents economics, Barcelona, Fundació Caixa de Pensions.

BYRNE, Patrick J., CAPPS, Oral, TSAI, Reyfong y WILLIAMS, Gary W. (1995): "Policy Implications of trade liberalization: The case of meat products in Taiwan and South Korea", Agribusiness, (11), 4, 297-307.

CAMPOFRÍO ALIMENTACIÓN (2000): Aumento de capital de Campofrío Alimentación, S.A. mediante emisión de acciones rescatable, Madrid, Campofrío Alimentación.

-(2002a-2006a): Memoria(s) anual(es) e informe(s) de gestión, Madrid, Grupo Campofrío.

-(2002b): Aumento del capital de Campofrío Alimentación por importe efectivo de 99.891.466,26 euros mediante la emisión de 13.160 .931 acciones ordinarias, Madrid, Campofrío Alimentación.

-(2004b): Informe del gobierno corporativo, Madrid, Campofrío Alimentación.

CÁRNICA 2.000 (1999): 1973-98.25 Aniversario, Madrid, Cárnica 2.000.

CASTELL, Pere (2001): “Els inicis de la industria càrnica a Osona, 1850-1920”, Estudis d'Història Agraria (14), pp. 255-294.

COMÍN COMÍN, Francisco (2000): “Los mitos y milagros de Suanzes: La empresa privada y el INI durante la Autarquía", Revista de Historia Industrial (18), pp. 221245.

COMÍN COMÍN, Francisco y MARTÍN ACEÑA, Pablo (1991): INI: 50 años de industrialización en España, Madrid, Espasa Calpe, D.L.

-(1999): Tabacalera y el estanco del tabaco en España, 1638-1998, Madrid, Fundación Tabacalera.

CONSERVAS CAMPOFRÍO (1975): Reglamento de régimen interior, Burgos, Conservas Campofrío.

ESCUELA SUPERIOR DE INDUSTRIAS CÁRNICAS (1966): El Jamón cocido (semi conserva), Madrid, Escuela Superior de Industrias Cárnicas.

EUROCARNE (2003): Carnes y productos cárnicos de calidad, Madrid, Estrategias Alimentarias, S.L.

FERNÁNDEZ PÉREZ, Paloma y PUIG RAPOSO, Nùria (2007): “Bonsáis in a wild forest? A historical interpretation of the longevity of large Spanish family firms", Revista de Historia Económica, XXV (3), pp. 459-497.

FISCHER, Rudolf, NOACK, Karl-Heinz y PFIEL, Wolfgang (1974): Industrias cárnicas. Cálculo de costos y de rendimientos, Zaragoza, Editorial Acribia

FOMENTO DE LA PRODUCCIÓN (1971-1989): Barcelona, Fomento de la Producción. 
GASÓLIBA, Carles A. (1972): Estudio económico de la industria cárnica, Banca Catalana, Barcelona.

GÓMEZ MENDOZA, Antonio (1994): “Del matadero a la tenería: Producción y consumo de pieles en España (1900-1933)", en NADAL, Jordi y CATALÁN, Jordi (eds.), La cara oculta de la industrialización española. La modernización de los sectores no líderes (siglos XIX y XX), Madrid, Alianza Editorial, pp. 267-293.

-(1995a): Hacia una economía del frío: El Plan de Red Frigorífica Nacional, Documento de Trabajo, Facultad de Ciencias Económicas y Empresariales, Universidad Complutense de Madrid.

—(1995b): “El Plan Frigorífico Español (1947-1951)”, en Revista de Historia Industrial, (8), pp. 147-170.

-(2000): “El Plan de Frío Industrial (1947/1951)", en GÓMEZ MENDOZA, Antonio (ed.), De mitos y milagros. El Instituto Nacional de Autarquía (1941-1963), Barcelona, Edicions Universitat de Barcelona y Fundación Duques de Soria, pp. 99-114. GÓMEZ MENDOZA, Antonio y SIMPSON, James (1988): “El consumo de carne en Madrid durante el primer tercio del siglo XX", Moneda y Crédito, (186), pp. 57-91. HAYES, Dermot j., AHN, Hyungdo, Baumel, Phillip (1991): “Meat demand in South Korea: A systems estimate and policy projections", Agribusiness, (7), 5, pp. 433446.

HERNÁNDEZ CRESPO, José Luis y PAZ SAÉZ, Antonio (1991): Panorama general de la industria alimentaria española. Situación y perspectiva. Industrias cárnicas y productos elaborados, Madrid, Ediciones Anaya, S.L.

HORMEL FOODS (1996-2006): Annual report(s), Austin (Virginia), Hormel Foods.

IZQUIERDO i ALCOLEA, Francecs (1972): Gerona ¿la despensa de España? Aportación al estudio económico de la industria cárnica del cerdo en las provincias de la comarca de Gerona, Gerona, Cámara de Comercio.

MARTÍNEZ CARRIÓN, José Miguel (1991): La ganadería en la economía murciana contemporánea, 1860-1936, Murcia, Consejería de Agricultura, Ganadería y Pesca.

-(2002): Historia Económica de la Región de Murcia, siglos XIX y XX, Murcia, Editora Regional.

-(2006): "Empresas y empresarios en la Región de Murcia", en GARCÍA RUIZ, José Luis y MANERA ERBINA, Carles (dirs.), Historia Empresarial de España: Un enfoque regional en profundidad, Madrid, Lid, pp. 391-423.

MINISTERIO DE AGRICULTURA (1953-1960): Resumen estadístico de la producción y valor de la carne, Madrid, Dirección General de Ganadería, Secretaría General, Estudios Pecuarios.

MINISTERIO DE AGRICULTURA, PESCA Y ALIMENTACIÓN (2007): El sector de la carne de cerdo en cifras. Principales indicadores económicos en 2006, Madrid, Subdirección General de Mercados Exteriores y Producción Porcinas, Avícolas y Otras. 
MORA, Cristina y MENOZZI, Dande (2005): "Vertical contractual relations in the Italian beef supply chain", Agribusiness, (21), 2, pp. 213-235.

NICOLAU NOS, Roser y PUJOL ANDREU, Josep (2004): “El consumo de proteínas animales en Barcelona entre las décadas de 1830 y 1930: Evolución y factores condicionantes", Investigaciones de Historia Económica (3), pp. 101-135.

PARREN, Richard (1978): The meat trade in Britain, 1840-1914, Londres, Routledge \& Kegan Paul.

-(2006): Taste, trade and technology. The development of the international meat industry since 1840, Aldershot, Ashgate.

PASCUAL RUIZ-VALDEPEÑAS, H. y ANDRÉS LÓPEZ, G., (2006): “Las primeras fábricas de la ciudad. El impulso industrializador de Burgos durante los años treinta y cuarenta", Revista de Historia Industrial (32), pp. 141-168.

POPE, C. Larry (2007a): Smithfield 2007 consumer analyst group of NY conference, Smithfield (Virginia), Smithfield Foods, Inc.

-(2007b): Smithfield Lehman brothers $1^{\text {st }}$ annual back to school consumer conference, Smithfield (Virginia), Smithfield Foods, Inc.

PUBLICACIONES ALIMARKET (1983-1992): Anuario, Madrid, Alimarket.

-(1993-2006): Informe Anual. Industrias perecederas, Madrid, Alimarket.

PUJOL ANDREU, Josep (2002): “Especialización ganadera, industrias agrarias y costes de transacción: Cataluña, 1880-1936", Historia Agraria, (27), pp. 191-220.

-(2003): "Sobre los orígenes de la industrialización en el sector agroalimentario; Cataluña, 1880-1945" en BARCIELA, Carlos y Di VITTORIO, Antonio (eds.), Las industrias agroalimentarias en España durante los siglos XIX y XX, Alicante, Publicaciones de la Universidad de Alicante, pp. 245-278.

RIXSON, Derrick (2000): The history of meat trading, Nottingham University Press, Nottingham.

ROCA i TRESCENTS, Josep y ROCA i PUIGVERT, Mercé (2004): Desarrollo y gestión de una transformación empresarial: Group Alimentari de Guissona, Barcelona, Group Alimentari de Guissona.

ROWE, M., (1996): "The amigo hunt", Strategic Direct Investor, Noviembre-diciembre, pp. 36-37.

SAN ROMÁN, Elena (1999): Ejército e industria: El Nacimiento del I.N.I., Barcelona, Crítica.

SANZ EGAÑA, César (1940): Industrias de la carne: Chacinería moderna (embutidos, salazones y conservas), Madrid, Espasa Calpe (segunda edición).

SKAGGS, Jimmy M. (1986): Prime cut. Livestock raising and meatpacking in the Unites States, Austin, Texas A\&M University Press.

SMITHFIELD FOOD, INC. (1996a-2006a): Annual report(s), Smithfield (Virginia), Smithfield Foods, Inc. 
-(2002b-2006b): Annual report(s) pursuant to section 13 or 15(d) of the securities exchange Act of 1935 for the fiscal year ended april, 29 (-), Washington, D.C., United States Securities and Exchange Commission.

-(2007): Smithfield. Porfile, Smithfield (Virginia), Smithfield Foods, Inc.

TORRADO, Llorenç (1985): Els embotits a Catalunya: Una tradioció, un art, una industria, Barcelona, Federació Catalana d'Industria de la Carn.

UNITED NATIONS CONFERENCE ON TRADE AND DEVELOPMENT (2002): World investment report, 2002. Par one: Trends in international production, chapter III. Regional trends, Ginebra, United Nations.

VARELA, Gregorio (2000): “El consumo de alimentos cuando se aleja el fantasma del hambre", en VELARDE FUERTES, Juan (coord.), 1900-200. Historia de un esfuerzo colectivo. Cómo España superó el pesimismo y la pobreza, Madrid, Fundación BSCH/Planeta tomo II, pp. 531-574.

VEGA HERERO, Cristina (2003): Cantimpalos. Apuntes sobre su "Historia y Progreso", Cantimpalos, La autora.

VICENT CHULIÁ, Francisco (2003): “Introducció” en VICENT CHULIÁ, Francisco et alli, El bon govern de les empreses familiars (Paper d'Economía Industrial, 18), Barcelona, Departament de Treball, Industria, Comerç i Turisme de la Generalitat de Catalunya.

YEAGER, Mary (1981): Competition and regulation: The development of oligopoly in the meat packing industry, Greewich (Connecticut), JAI Press Inc.

YORUK, Deniz Eylem (2001): "Growth of a Polish meat company: merger and acquisitions and the role of strategic investors", documento de trabajo, Economic \& Social Research Council, Londres.

WALSH, Margaret (1982): The rise of the midwestern meat packing industry, Lexington, The University Press of Kentucky.

WARD, Clement E. (1993): "Comparative analysis of cattle slaughtering and fabricating cost", Agribusiness, (9), pp. 441-451.

ZAPATA, Manuel (1986): Las industrias cárnicas de la Región de Murcia, Murcia, CSIC. 


\section{APÉNDICE 1}

EMPRESAS INTEGRANTES DEL GRUPO CAMPOFRÍO EN JULIO DE 2000

(participación en porcentajes)

\begin{tabular}{|c|c|c|c|c|c|}
\hline Razón Social & Año & Domicilio & $\begin{array}{c}\text { País/ } \\
\text { Provincia }\end{array}$ & $\begin{array}{l}\text { Objeto } \\
\text { Social }\end{array}$ & $\begin{array}{l}\text { Partici- } \\
\text { pación }\end{array}$ \\
\hline Conservera Campofrío & 1944 & Madrid & Madrid & Elaboración & 100,00 \\
\hline OMSA (1) & 1957 & Valencia & Valencia & Elaboración & 57,02 \\
\hline La Montanera & 1987 & Torrijos & Toledo & Elaboración & 100,00 \\
\hline 814 Americas Inc & 2000 & New Jersey & EEUU & Elaboración & 100,00 \\
\hline Campo Austral & 1993 & Buenos Aires & Argentina & Elaboración & 40,00 \\
\hline Jamones de Soria & 1994 & Los Rábanos & Soria & Elaboración & 25,03 \\
\hline Navidul Extremadura & 1997 & Madrid & Madrid & Elaboración & 40,00 \\
\hline San Miguel Campocarne Co. & 1991 & Manila & Filipinas & Elaboración & 50,00 \\
\hline Comercial Villar SXXI & 1999 & Los Rábanos & Soria & Elaboración & 25,00 \\
\hline Industrias Cárnicas Revilla & 1971 & Madrid & Madrid & Elaboración & 100,00 \\
\hline Campofrío Montagne Noire & 1990 & Fenouillet & Francia & Elaboración & 80,00 \\
\hline SC Tabco & 1991 & Tulcea & Rumanía & Elaboración & 95,61 \\
\hline CampoMos & 1990 & Moscú & Rusia & Elaboración & 91,00 \\
\hline Campocarne & 1984 & Madrid & Madrid & Elaboración & 100,00 \\
\hline Morliny, SA (2) & 1972 & Ostroda & Polonia & Elaboración & 98,92 \\
\hline \multicolumn{6}{|l|}{ Delicass Sociedad } \\
\hline de Alimentación & 1991 & Vizcaya & & Elaboración & 100,00 \\
\hline Valpro Alimentación & 1994 & Valencia & Valencia & Elaboración & 100,00 \\
\hline Castileon 2000 & n.d. & Burgos & Burgos & Crianza & n.d. \\
\hline Degarposa & n.d. & Burgos & Burgos & Crianza & 40,00 \\
\hline Degesa & 1975 & Burgos & Burgos & Crianza & 10,00 \\
\hline Grupo Navidul Portugal Ltd & 1997 & Lisboa & Portugal & Comercialización & 100,00 \\
\hline Navidul Argentina & 1995 & Buenos Aires & Argentina & Comercialización & 100,00 \\
\hline Navidul Comercial France & 1993 & Tanninges & Francia & Comercialización & 100,00 \\
\hline \multicolumn{6}{|l|}{ Navidul Especialidades } \\
\hline Europeas & 1998 & Madrid & Madrid & Comercialización & 33,33 \\
\hline \multicolumn{6}{|l|}{ Bretta Especialidades } \\
\hline Europeas & 1999 & París & Francia & Comercialización & 33,33 \\
\hline \multicolumn{6}{|l|}{ Fleury Michon Specialités } \\
\hline D’Europe & 1958 & París & Francia & Comercialización & 33,33 \\
\hline NBF Brasil, Ltda... & 1998 & Sao Paulo & Brasil & Comercialización & 33,33 \\
\hline \multicolumn{6}{|l|}{ Conservera Campofrío } \\
\hline Portuguesa & 1991 & Lisboa & Portugal & Comercialización & 100,00 \\
\hline
\end{tabular}




\section{APÉNDICE 1 (continuación)}

EMPRESAS INTEGRANTES DEL GRUPO CAMPOFRÍO EN JULIO DE 2000

(participación en porcentajes)

\begin{tabular}{lrlllr}
\hline \multicolumn{1}{c}{ Razón Social } & Año & Domicilio & $\begin{array}{c}\text { País/ } \\
\text { Provincia }\end{array}$ & $\begin{array}{c}\text { Objeto } \\
\text { Social }\end{array}$ & $\begin{array}{r}\text { Partici- } \\
\text { pación }\end{array}$ \\
\hline Distribuciones León & 1996 & Jerez & Cádiz & Comercialización & 50,00 \\
OMSA AlimentaÇao Portugal & 1994 & Lisboa & París & Comercialización & 100,00 \\
OMSA alimentación, SARL & 1996 & París & Francia & Comercialización & 100,00 \\
Nividul cogeneración & 1997 & Madrid & Madrid & Energía & 45,00 \\
Cogeneradora Burgalesa & 1996 & Burgos & Burgos & Energía & 50,00 \\
Tanki International Holding BV & 1989 & Haalem & Holanda & Instrumental & 100,00 \\
Sandridge Trading Ltd & 1996 & Islas Vírgenes & Reino Unido & Instrumental & 49,78 \\
Matadero Villar & 1999 & Los Rábanos & Soria & Sacrificio & 25,00 \\
Frigotrans & n.d. & Mem-Martins & Portugal & Transporte & 100,00 \\
Campoimport & 1994 & Moscú & Rusia & En liquidación & 100,00 \\
Toreador & 1994 & Moscú & Rusia & En liquidación & 75,00 \\
\hline
\end{tabular}

(1): Incluye las sociedades dependientes

(2): Incluye las sociedades dependientes Transport Morliny Sp. Z.o.o., Detal Morlny_Sp. Z.o.o. y Rowena.

Fuente: Campofrío Alimentación (2000) y (2002), CNMV, Campofrío Alimentación, Cuentas anuales e informe de gestión, 2000 y elaboración propia. 


\section{APÉNDICE 2}

EL ENTRAMADO EMPRESARIAL DEL CORPORATIVO FUERTES EN 2001

\begin{tabular}{|c|c|c|c|c|}
\hline Empresa & Objeto Social & Domicilio & $\begin{array}{c}\text { País/ } \\
\text { Provincia }\end{array}$ & $\begin{array}{l}\text { Partici- } \\
\text { pación }\end{array}$ \\
\hline El Pozo Alimentación, S.A. & Productos cárnicos & Alahama & Murcia & 100,00 \\
\hline Fripozo,S.A. & Alimentos congelados & Alahama & Murcia & 100,00 \\
\hline Procavi, S.L. & Carne de pavo & Marchena & Murcia & 100,00 \\
\hline SARL Fuertes France & Comercialización & Toulusse & Francia & 100,00 \\
\hline Fuertes Portugal LDA & Comercialización & Lisboa & Portugal & 100,00 \\
\hline Agrifusa & Cultivo cereales y frutas & Alahama & Murcia & 100,00 \\
\hline Cefusa & Ganadería porcina & Alahama & Murcia & 100,00 \\
\hline Agrios EI Carril & Manipulación de cítricos & Santomera & Murcia & 22,00 \\
\hline Plátanos del Sur, S.L. & Horticultura & Almería & Almería & 50,00 \\
\hline \multicolumn{5}{|l|}{ Transformación Agraria } \\
\hline La Solana & Horticultura & Alahama & Murcia & 56,70 \\
\hline Fuente Arquillo, S.L. & Embotellado de agua & Alahama & Murcia & 100,00 \\
\hline AEMEDSA & Pretroquímica & Murcia & Murcia & 100,00 \\
\hline Esteros del Atlántico & Piscifactoría & Cádiz & Cádiz & 100,00 \\
\hline Profusa & Construcción & Murcia & Murcia & 100,00 \\
\hline Montevida, S.A. & Construcción & Murcia & Murcia & 100,00 \\
\hline Vishoteles, S.L. & Hotel & Albufereta & Alicante & 100,00 \\
\hline Olimpic Club de Murcia, S.L. & Ocio & Murcia & Murcia & 100,00 \\
\hline Terra Mítica, S.A. & Ocio & Benidorm & Alicante & 5,00 \\
\hline Terra Natura, S.A. & Ocio & Benidorm & Alicante & 26,00 \\
\hline Ono & Telecomunicaciones & Madrid & Madrid & 1,54 \\
\hline Neo & Telecomunicaciones & Madrid & Madrid & 2,57 \\
\hline Energías Fotovoltaicas de Murcia & Energías renovables & Murcia & Murcia & 12,50 \\
\hline Energías Renovables de Murcia & Energías renovables & Murcia & Murcia & 10,00 \\
\hline Autopista del Sureste & Autopistas & Murcia & Murcia & 20,00 \\
\hline Control Hospitalario, D.L. & Infraestructuras sanitarias & Alicante & Alicante & 30,86 \\
\hline Todagrés & Fabricación de azulejos & Villareal & Castellón & 30,86 \\
\hline
\end{tabular}

Fuente: Publicaciones Alimarket (2002), pássim. 